\title{
MEMS Length and Strain Round Robin Results with Uncertainty Analysis
}

\author{
Janet C. Marshall \\ Robert I. Scace \\ Winthrop A. Baylies
}

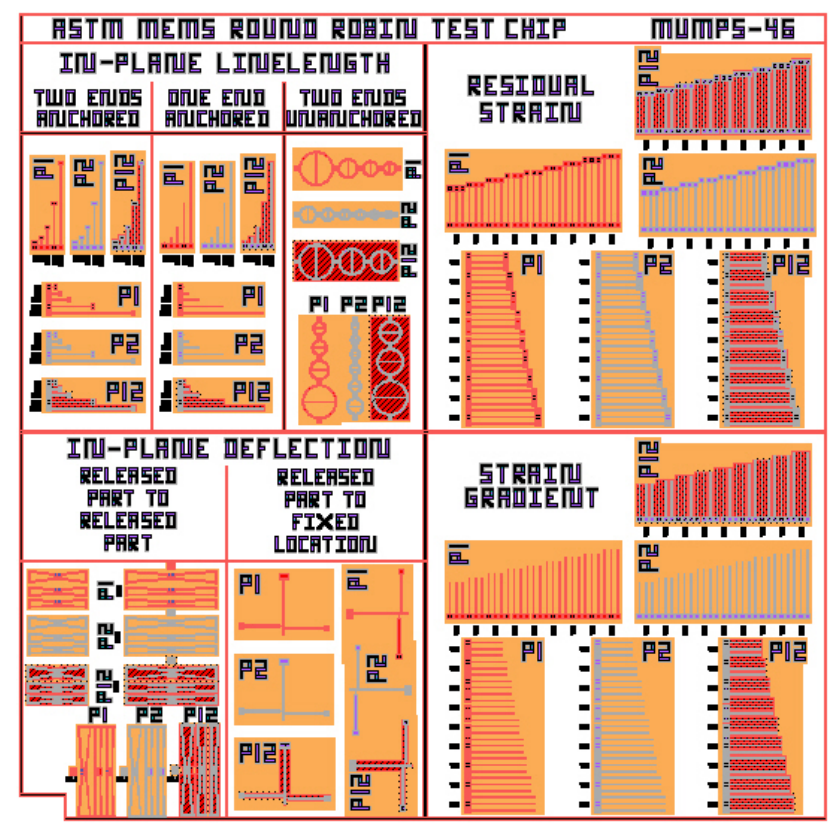


NISTIR 7291

\title{
MEMS Length and Strain Round Robin Results with Uncertainty Analysis
}

\author{
Janet C. Marshall \\ Semiconductor Electronics Division \\ Electronics and Electrical Engineering Laboratory \\ National Institute of Standards and Technology \\ Gaithersburg, MD 20899-8120 \\ Robert I. Scace \\ President, Klaros Corporation \\ Beallsville, MD 20839-3314 \\ Winthrop A. Baylies \\ President, BayTech Group \\ Weston, MA 02493
}

January 2006

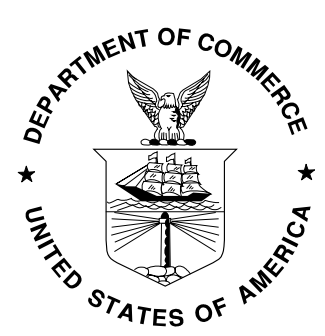

\section{U.S. DEPARTMENT OF COMMERCE Carlos M. Gutierrez, Secretary TECHNOLOGY ADMINISTRATION} Michelle O'Neill, Acting Under Secretary of Commerce for Technology NATIONAL INSTITUTE OF STANDARDS AND TECHNOLOGY William Jeffrey, Director 



\section{TABLE OF CONTENTS}

Abstract

1. Introduction

2. Interferometer Specifications and Round Robin Test Chip . . . . . . . . . . . . . . . . 2

2.1 Interferometer Specifications . . . . . . . . . . . . . . . . . . . . . . . . 2

2.2 Round Robin Test Chip . . . . . . . . . . . . . . . . . . . . . . . . . . 3

3. Round Robin Measurement Procedure c . . . . . . . . . . . . . . . . . . . . . . . 3

3.1 In-Plane Length Measurements . . . . . . . . . . . . . . . . . . . . . . . 3

3.2 Residual Strain Measurements . . . . . . . . . . . . . . . . . . . . . . . 4

3.3 Strain Gradient Measurements . . . . . . . . . . . . . . . . . . . . . . . 4

4. Uncertainty Calculations . . . . . . . . . . . . . . . . . . . . . . . . . . . . . 5

4.1 The Combined Standard Uncertainty Equation . . . . . . . . . . . . . . . . . 5

4.2 In-Plane Length Uncertainty Calculations . . . . . . . . . . . . . . . . . . . 5

4.3 Residual Strain Uncertainty Calculations . . . . . . . . . . . . . . . . . . . 6

4.4 Strain Gradient Uncertainty Calculations ． . . . . . . . . . . . . . . . . . . 9

5. Round Robin Results . . . . . . . . . . . . . . . . . . . . . . . . . . . . . . 11

5.1 In-Plane Length Results . . . . . . . . . . . . . . . . . . . . . . . . . . 11

5.2 Residual Strain Results . . . . . . . . . . . . . . . . . . . . . . . . . . 13

5.3 Strain Gradient Results . . . . . . . . . . . . . . . . . . . . . . . . . . 14

6. Conclusions . . . . . . . . . . . . . . . . . . . . . . . . . . . . . . . . . . 15

7. Acknowledgment . . . . . . . . . . . . . . . . . . . . . . . . . . . . . . . 15

8. References . . . . . . . . . . . . . . . . . . . . . . . . . 15

\section{LIST OF FIGURES}

1. The round robin test chip. . . . . . . . . . . . . . . . . . . . . . . . . . . . . 1

2. Top view of a fixed-fixed beam test structure . . . . . . . . . . . . . . . . . . . . . 2

3. An example of a 2-D data trace taken between the anchors of a fixed-fixed beam test structure . 2

4. Schematic of an optical interferometer . . . . . . . . . . . . . . . . . . . . . . . 2

5. Two data sets derived from an abbreviated data trace along a fixed-fixed beam . . . . . . . . 4

6. Top view of a cantilever test structure . . . . . . . . . . . . . . . . . . . . . . . . 4

7. An example of a 2-D data trace adjacent to a cantilever . . . . . . . . . . . . . . . . . . 4

8. A 2-D data trace used to find three data points . . . . . . . . . . . . . . . . . . . . . . . 5

9. Reproducibility and repeatability bias data for $L$. . . . . . . . . . . . . . . . . . . . . . . . . 12

10. Comparing reproducibility and repeatability results for $u_{\text {cave }}$ in Data Sheet A . . . . . . . . 13

11. Comparing reproducibility and repeatabiltiy results for $u_{\text {cave }}$ in Data Sheet B . . . . . . . . 13

12. A plot of $-\varepsilon_{r}$ versus orientation . . . . . . . . . . . . . . . . . . . . . . . . . . . 14

13. A plot of $-\varepsilon_{r}$ versus length . . . . . . . . . . . . . . . . . . . . . . . . . . . . 14

14. A plot of $s_{g}$ versus orientation . . . . . . . . . . . . . . . . . . . . . . . . . . . 15

15. A plot of $s_{g}$ versus length for two different orientations . . . . . . . . . . . . . . . . . 15 


\section{LIST OF TABLES}

Page

1. Interferometer Pixel-to-Pixel Spacing Requirements . . . . . . . . . . . . . . . . . . 2

2. Quadrant, Measurement, and Associated Test Structures for the MEMS Round Robin Test Chip in Figure 1 . . . . . . . . . . . . . . . . . . . . . . . . . . . . . . . . 3

3. Determination of the Residual Strain Uncertainty Components . . . . . . . . . . . . . . 6

4. Seven Sets of Inputs for Residual Strain Calculations to Determine $u_{\text {zres }}, u_{\text {samp }}, u_{\text {Rave }}$, and $u_{\text {noise }}$. 7

5. Three Sets of Inputs for Residual Strain Calculations to Determine $u_{\text {zcal }}, u_{\text {cert }}, u_{\text {repeat }}, u_{\text {drift }}$, and $u_{\text {linear }}$. . . . . . . . . . . . . . . . . . . . . . . . . . . . . . . . . . . . . . . . . . . . . . . .

6. Seven Sets of Inputs for Residual Strain Calculations to Determine $u_{x r e s}$. . . . . . . . . . . . 8

7. Two Sets of Inputs for Residual Strain Calculations to Determine $u_{x r e s L} \quad$. . . . . . . . . . . . . 8

8. Determination of the Strain Gradient Uncertainty Components . . . . . . . . . . . . . . 10

9. Three Sets of Inputs for Strain Gradient Calculations to Determine $u_{\text {zres }}, u_{\text {samp }}, u_{\text {Rave }}$ and $u_{\text {noise }} \quad$. 10

10. Three Sets of Inputs for Strain Gradient Calculations to Determine $u_{\text {zcal }}, u_{\text {cert }}, u_{\text {repeat }}, u_{\text {drift }}$, and $u_{\text {linear }}$. . . . . . . . . . . . . . . . . . . . . . . . . . . . . . . . . . . . . . . . . 10

11. Seven Sets of Inputs for Strain Gradient Calculations to Determine $u_{x r e s}$. . . . . . . . . . . 10

12. Reproducibility of Round Robin Measurement Results for In-Plane Length Measurements When the Transitional Edges Face Each Other . . . . . . . . . . . . . . . . . . . . 11

13. Repeatability of NIST Measurement Results for In-Plane Length Measurements When the Transitional Edges Face Each Other . . . . . . . . . . . . . . . . . . . . . . . . 11

14. Reproducibility of Round Robin Measurement Results for In-Plane Length Measurements When the Transitional Edges Face the Same Direction . . . . . . . . . . . . . . . . . 12

15. Repeatability of NIST Measurement Results for In-Plane Length Measurements When the Transitional Edges Face the Same Direction . . . . . . . . . . . . . . . . . . . . . 12

16. Residual Strain Measurement Results . . . . . . . . . . . . . . . . . . . . . . . . 14

17. Strain Gradient Measurement Results . . . . . . . . . . . . . . . . . . . . . . . . 14

\section{LIST OF SYMBOLS}

For calibration:

$\mu \quad=$ the mean value of the step-height measurements (on the double-sided step height standard) used to calculate $\mathrm{cal}_{z}$.

$\mu_{6} \quad=$ the average of the six calibration measurements from which $z_{\text {repeat }}$ was found.

$\sigma_{c e r t} \quad=$ the certified one sigma uncertainty of the certified step height standard.

$\sigma_{x c a l} \quad=$ the standard deviation in a ruler measurement in the interferometer's $x$-direction for the given combination of lenses.

$\sigma_{z c a l} \quad=$ the standard deviation of the step height measurements (on the double-sided step height standard).

calave $_{\text {after }}=$ the average of the six calibration measurements taken after the data session.

calave $_{\text {before }}=$ the average of the six calibration measurements taken before the data session.

$\operatorname{cal}_{x} \quad=$ the $x$-calibration factor of the interferometer for the given combination of lenses.

cal $_{\text {xmax }} \quad=$ the maximum $x$-calibration factor.

cal $_{x \text { min }} \quad=$ the minimum $x$-calibration factor.

$\mathrm{cal}_{z} \quad=$ the $z$-calibration factor of the interferometer for the given combination of lenses.

cert $\quad=$ the certified value of the double-sided step height standard. 
inter $_{x} \quad=$ the interferometer's maximum field of view in the $x$-direction for the given combination of lenses.

$\operatorname{ruler}_{x} \quad=$ the interferometer's maximum field of view in the $x$-direction for the given combination of lenses as measured with a $10 \mu \mathrm{m}$ grid (or finer grid) ruler.

For in-plane length, residual strain, and strain gradient measurements:

$\varepsilon_{r} \quad=$ the residual strain.

$L \quad=$ the in-plane length measurement.

$L_{\max } \quad=$ the maximum in-plane length measurement.

$L_{\min } \quad=$ the minimum in-plane length measurement.

sep $\quad=$ the average calibrated separation between two interferometric pixels as applies to a given measurement.

$s_{g} \quad=$ the strain gradient as calculated from three data points.

$x 1_{\text {lower }} \quad=$ the $x$-data value along Edge " 1 " locating the lower part of the transitional edge.

$x l_{\max } \quad=$ the smaller of the two $x$ values $\left(x 1_{\text {lower }}\right.$ or $\left.x 1_{\text {upper }}\right)$ used to calculate $L_{\max }$.

$x l_{\min } \quad=$ the larger of the two $x$ values $\left(x l_{\text {lower }}\right.$ or $\left.x l_{\text {upper }}\right)$ used to calculate $L_{\min }$.

$x 1_{\text {upper }} \quad=$ the $x$-data value along Edge " 1 " locating the upper part of the transitional edge.

$x 2_{\text {lower }} \quad=$ the $x$-data value along Edge " 2 " locating the lower part of the transitional edge.

$x 2_{\max }=$ the larger of the two $x$ values $\left(x 2_{\text {lower }}\right.$ or $\left.x 2_{\text {upper }}\right)$ used to calculate $L_{\max }$.

$x 2_{\min }=$ the smaller of the two $x$ values $\left(x 2_{\text {lower }}\right.$ or $\left.x 2_{\text {upper }}\right)$ used to calculate $L_{\text {min }}$.

$x 2_{\text {upper }} \quad=$ the $x$-data value along Edge " 2 " locating the upper part of the transitional edge.

$x_{\text {lower }} \quad=$ the $x$-data value along the transitional edge of interest locating the lower part of the transition.

$x_{\text {upper }} \quad=$ the $x$-data value along the transitional edge of interest locating the upper part of the transition.

For combined standard uncertainty calculations:

$\varepsilon_{\text {-high }}=$ in determining the combined standard uncertainty value for the residual strain measurement, the highest value for $\varepsilon_{r}$ given the specified variations.

$\varepsilon_{\text {r-low }}=$ in determining the combined standard uncertainty value for the residual strain measurement, the lowest value for $\varepsilon_{r}$ given the specified variations.

$\sigma_{\text {noise }} \quad=$ the standard deviation of the noise measurement, calculated to be one-sixth the value of $R_{\text {tave }}$ minus $R_{\text {ave }}$.

$\sigma_{\text {Rave }} \quad=$ the standard deviation of the surface roughness measurement, calculated to be one-sixth the value of $R_{\text {ave }}$.

$\sigma_{\text {samp }} \quad=$ the standard deviation in a height measurement due to the sample's peak-to-valley surface roughness as measured with the interferometer.

$L_{\text {maxres }} \quad=$ the maximum length as determined from the resolution of the interferometer in the $x$ direction.

$L_{\text {maxxcal }} \quad=$ the maximum length as determined from the maximum $x$-calibration factor.

$L_{\text {minres }}$

$L_{\text {minxcal }} \quad=$ the minimum length as determined from the minimum $x$-calibration factor.

$R_{\text {ave }} \quad=$ the surface roughness of a flat and leveled surface of the sample material calculated to be the average of three or more measurements, each measurement of which is taken from a different 2-D data trace.

$R_{\text {tave }} \quad=$ the peak-to-valley roughness of a flat and leveled surface of the sample material calculated to be the average of three or more measurements, each measurement of which is taken from a different 2-D data trace. 


\begin{tabular}{|c|c|}
\hline Sg-high & $\begin{array}{l}=\text { in determining the combined standard uncertainty value for the strain grac } \\
\text { measurement, the highest value for } s_{g} \text { given the specified variations. }\end{array}$ \\
\hline$S_{g-l o w}$ & $\begin{array}{l}\text { in determining the combined standard uncertainty value for the strain gradien } \\
\text { leasurement, the lowest value for } s_{g} \text { given the specified variations. }\end{array}$ \\
\hline$u_{c}$ & $\begin{array}{l}\text { the combined standard uncertainty value (that is, the estimated standard deviation of the } \\
\text { sult). }\end{array}$ \\
\hline$u_{\text {cert }}$ & $\begin{array}{l}\text { the component in the combined standard uncertainty calculation that is due to the } \\
\text { acertainty of the value of the step-height standard. }\end{array}$ \\
\hline$u_{\text {drift }}$ & $\begin{array}{l}\text { the component in the combined standard uncertainty calculation that is due to the amount } \\
\text { f drift during the data session. }\end{array}$ \\
\hline$u_{L}$ & $\begin{array}{l}\text { the component in the combined standard uncertainty calculation that is due to the } \\
\text { neasurement uncertainty of } L \text {. }\end{array}$ \\
\hline$u_{\text {linear }}$ & $\begin{array}{l}\text { the component in the combined standard uncertainty calculation that is due to the } \\
\text { eviation from linearity of the data scan. }\end{array}$ \\
\hline$u_{\text {noise }}$ & $\begin{array}{l}\text { the component in the combined standard uncertainty calculation that is due to } \\
\text { nterferometric noise. }\end{array}$ \\
\hline$u_{\text {Rave }}$ & $\begin{array}{l}=\text { the component in the combined standard uncertainty calculation that is due to the } \\
\text { sample's surface roughness as measured with the interferometer. }\end{array}$ \\
\hline$u_{\text {repeat }}$ & $\begin{array}{l}\text { the component in the combined standard uncertainty calculation that is due to the } \\
\text { peatability of a measurement. }\end{array}$ \\
\hline$u_{\text {samp }}$ & $\begin{array}{l}\text { the component in the combined standard uncertainty calculation that is due to the } \\
\text { ample's peak-to-valley surface roughness as measured with the interferometer. }\end{array}$ \\
\hline$u_{W}$ & $\begin{array}{l}\text { the component in the combined standard uncertainty calculation that is due to the } \\
\text { eeasurement uncertainty across the width of the beam. }\end{array}$ \\
\hline$u_{x c a l}$ & $\begin{array}{l}=\text { the component in the combined standard uncertainty calculation that is due to the } \\
\text { uncertainty of the calibration in the } x \text {-direction. }\end{array}$ \\
\hline$u_{x r e s}$ & $\begin{array}{l}=\text { the component in the combined standard uncertainty calculation that is due to the } \\
\text { resolution of the interferometer in the } x \text {-direction. (For residual strain calculations, this is } \\
\text { restricted to the chosen data points along the beam.) }\end{array}$ \\
\hline$u_{x r e s L}$ & $\begin{array}{l}=\text { the component in the combined standard uncertainty calculation for residual strain that is } \\
\text { due to the resolution of the interferometer in the } x \text {-direction as pertains to the in-plane } \\
\text { length measurement. }\end{array}$ \\
\hline$u_{z c a l}$ & $\begin{array}{l}=\text { the component in the combined standard uncertainty calculation that is due to the } \\
\text { uncertainty of the calibration in the } z \text {-direction. }\end{array}$ \\
\hline$u_{\text {zres }}$ & $\begin{array}{l}=\text { the component in the combined standard uncertainty calculation that is due to the } \\
\text { resolution of the interferometer in the } z \text {-direction. }\end{array}$ \\
\hline$w_{1 / 2}$ & $\begin{array}{l}=\text { the half width of the interval from } \varepsilon_{r-\text { low }} \text { to } \varepsilon_{r \text {-high }} \text { or the half width of the interval from } s_{g-} \\
\text { low to } s_{\text {g-high }} \text {. }\end{array}$ \\
\hline$x_{\text {res }}$ & $=$ the resolution of the interferometer in the $x$-direction. \\
\hline$z_{\text {drift }}$ & $=$ the positive difference between calave $e_{\text {before }}$ and calave $e_{\text {after }}$. \\
\hline$z_{\text {linear }}$ & $=$ the difference in height between two points times $z_{\text {perc }}$ and divided by 100 . \\
\hline$z_{\text {perc }}$ & $\begin{array}{l}=\text { the percent quoted by the interferometer manufacturer for the maximum deviation from } \\
\text { linearity of the data scan over the total scan range divided by } 1 \% \text { such that it is unitless. }\end{array}$ \\
\hline$z_{\text {repeat }}$ & $\begin{array}{l}=\text { the maximum of two values; one of which is the positive difference between the } \\
\text { minimum and maximum values of the six calibration measurements taken before the data } \\
\text { session and the other is the positive difference between the minimum and maximum values } \\
\text { of the six measurements taken after the data session. }\end{array}$ \\
\hline & s \\
\hline
\end{tabular}


For round robin measurements:

$\Delta L=$ for the given value of $L_{\text {des }}, L_{\text {ave }}$ minus $L_{\text {des }}$.

$\Delta L_{\text {ave }} \quad=$ the average value of $\Delta L$ over the given range of $L_{d e s}$ values.

$\varepsilon_{\text {rave }} \quad=$ the average residual strain value for the reproducibility or repeatability measurements. It is equal to the sum of the $\varepsilon_{r}$ values divided by $n$.

$L_{\text {ave }} \quad=$ the average in-plane length value for the reproducibility or repeatability measurements. It is equal to the sum of the $L$ values divided by $n$.

$L_{\text {des }} \quad=$ the design length.

$\operatorname{mag} \quad=$ the magnification used for the measurement.

$n \quad=$ the number of reproducibility or repeatability measurements.

$s_{\text {gave }} \quad=$ the average strain gradient value for the reproducibility or repeatability measurements. It is equal to the sum of the $s_{g}$ values divided by $n$.

$u_{\text {cave }} \quad=$ the average combined standard uncertainty value for the reproducibility or repeatability measurements. It is equal to the sum of the $u_{c}$ values divided by $n$. 


\section{MEMS Length and Strain Round Robin Results with Uncertainty Analysis}

\author{
Janet C. Marshall, Robert I. Scace,* \\ and Winthrop A. Baylies** \\ Semiconductor Electronics Division \\ National Institute of Standards and Technology \\ Gaithersburg, MD 20899-8120 \\ * Klaros Corporation \\ Beallsville, MD 20839-3314 \\ ** BayTech Group \\ Weston, MA 02493
}

\section{Abstract}

A microelectromechanical systems (MEMS) Length and Strain Round Robin Experiment was completed in January 2005 to compare results of in-plane length measurements, residual strain measurements, and strain gradient measurements at a number of laboratories. This paper ${ }^{1}$ presents the results from this MEMS Length and Strain Round Robin Experiment and the uncertainties associated with the measurements. The final results satisfy the requirements for the formulation of precision and bias statements in three related American Society for Testing and Materials (ASTM) standard test methods for MEMS.

The goal of the round robin was to assess the reproducibility of measurements performed using the same test method at independent laboratories as well as the repeatability of measurements performed using the same test method, in the same laboratory, by the same operator, with the same equipment, in the shortest practicable period of time. Both the reproducibility and repeatability measurements were done on essentially random test units made of the same homogeneous material.

The outcome of this round robin is a step towards assuring high quality data, which will help reduce the laboratory-to-laboratory differences in the parametric measurements.

\section{Introduction}

Microelectromechanical systems (MEMS) is a rapidly growing complement to the semiconductor industry. Applications for MEMS demand high performance and reliability. The first MEMS standards [1-3] were approved by ASTM in 2002. These standards are expected to facilitate commerce in MEMS technologies and improve manufacturing yields by decreasing interlaboratory differences in measurement.

Contribution of the National Institute of Standards and Technology (NIST); not subject to copyright in the U.S.
The ASTM test methods are used for measuring inplane lengths or deflections, ${ }^{2}$ residual strain, ${ }^{3}$ and strain gradient. $^{4}$ They employ a non-contact measurement approach using an optical interferometer. These test methods were used in a round robin to determine their repeatability as well as to see if independent laboratories could reproduce these measurements without introducing a bias.

In addition, for each measurement, the combined standard uncertainty [4] (which is comparable to the estimated standard deviation of the result) is determined. Individual uncertainty components are specified in this report and included in the analysis.

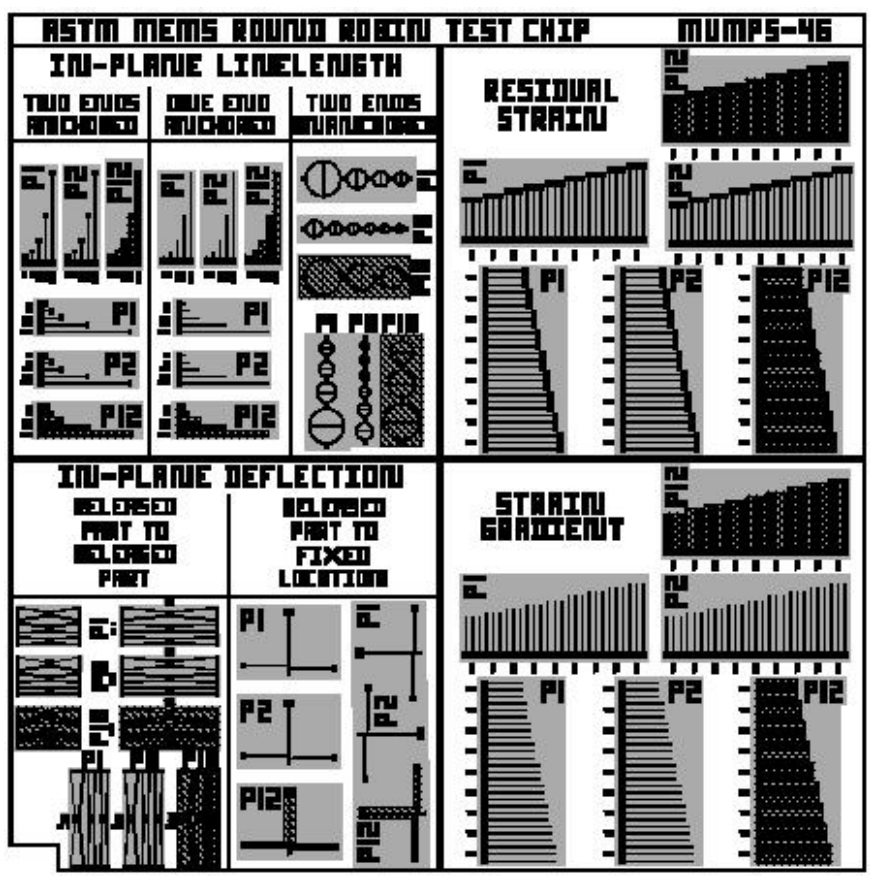

Figure 1. The round robin test chip.

In the round robin, a test chip (the design of which is shown in Figure 1) was passed from laboratory to laboratory, and measurements were taken on random test units using the procedures of the ASTM test methods. Data (i.e., $x$ or $y$ and/or $z$ values) from these measurements were analyzed using a NIST web-based program that also verifies the data before submitting the results to NIST [5]. Eight laboratories (NIST, Kavlico, Motorola, Lucent Technologies, Veeco Metrology, Zygo, FLX Micro, and Delphi) participated in the round robin.

\footnotetext{
An in-plane length (or deflection) measurement is defined as the experimental determination of the straight-line distance between two transitional edges in a MEMS device.

Residual strain is defined in a MEMS process as the amount of deformation (or displacement) per unit length constrained within the structural layer of interest after fabrication yet before the constraint of the sacrificial layer (or substrate) is removed (in whole or in part).

4 Strain gradient is defined as a through-thickness variation (of the residual strain) in the structural layer of interest before it is released.
} 
The participants were instructed to use the three ASTM standard test methods in performing their measurements. The first test method (E 2244) [6] is for measuring in-plane lengths. This test method is used when measuring in-plane deflections and when measuring lengths in fabrication processes that are being developed. Two transitional edges (such as Edges " 1 " and " 2 " in Figures 2 and 3) are chosen that define the in-plane length measurement. (A transitional edge is an edge of a MEMS structure that is characterized by a distinctive out-of-plane displacement.) At each transitional edge defining the in-plane length measurement, values defining a minimum and maximum length measurement are obtained. The minimum and maximum lengths are calculated, and the in-plane length is the average of these two values. [Alternatively, if the transitional edges that define the in-plane length measurement face the same way and have similar slopes and magnitudes (such as Edges " 1 " and " 5 " in Figures 2 and 3), a different approach can be taken. Here, an $x$-value is obtained at the lower (or upper) portion of each transitional edge. The smaller $x$ value is subtracted from the larger $x$ value to find the in-plane length.]

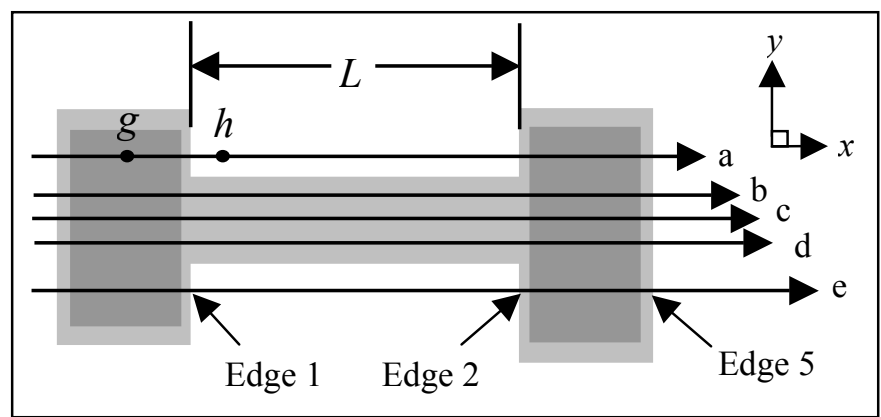

Figure 2. Top view of a fixed-fixed beam test structure.

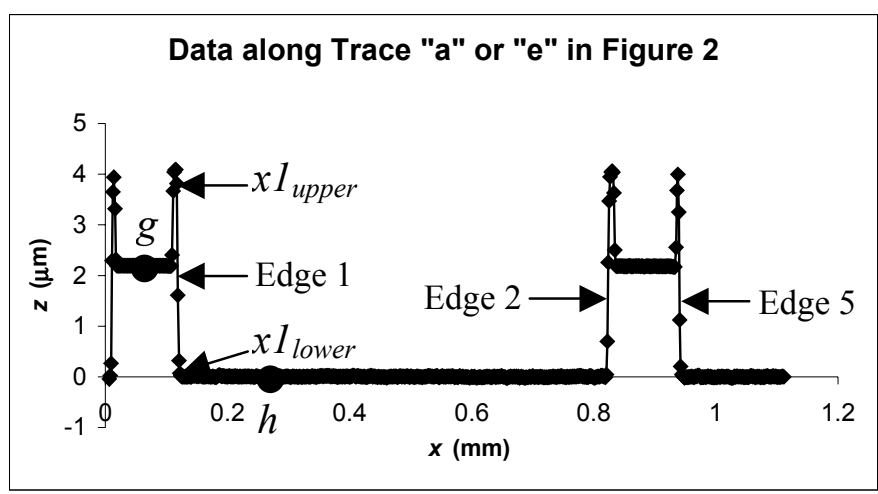

Figure 3. An example of a 2-D data trace taken between the anchors of a fixed-fixed beam test structure.

The second test method (E 2245) [6] measures the residual strain. This value is important to aid in the design and fabrication of MEMS devices. Three data points are obtained to define each function that characterizes the outof-plane shape of fixed-fixed beams. Two cosine functions are used to model the shape. Therefore, five independent data points are required, since one data point is common to both functions. The residual strain is calculated after the appropriate lengths are determined.

The third test method (E 2246) [6] measures the strain gradient. Given this value, and the definition of a "flat" or "straight" cantilever for the given application, the maximum length of such a cantilever can be determined. Three data points are obtained to define an arc of a circle that is used to model the out-of-plane shape of cantilevers. The strain gradient is calculated from the radius of the circle.

\section{Interferometer Specifications and Round Robin Test Chip}

\subsection{Interferometer Specifications}

The tool required for the round robin was a non-contact optical interferometer capable of obtaining a topographical $3-\mathrm{D}$ data set and exporting a 2-D data trace. Figure 4 is a schematic of such an interferometer. This non-contact optical interferometer must have pixel-to-pixel spacings as specified in Table 1 and a vertical resolution better than 1 nm. This resolution may be obtained by averaging multiple measurements. The interferometer must be capable of measuring step heights to at least $5 \mu \mathrm{m}$ higher than the step height to be measured.

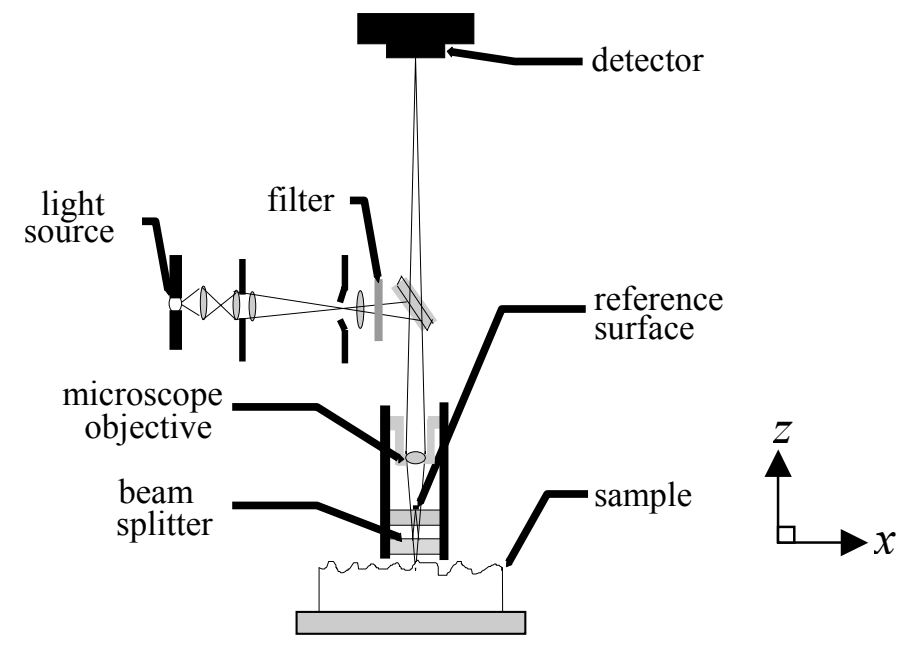

Figure 4. Schematic of an optical interferometer.

Table 1. Interferometer Pixel-to-Pixel Spacing Requirements

\begin{tabular}{|c|c|}
\hline Magnification, $\boldsymbol{x}$ & Pixel-to-pixel spacing, $\boldsymbol{\mu m}$ \\
\hline 5 & $<1.57$ \\
\hline 10 & $<0.83$ \\
\hline 20 & $<0.39$ \\
\hline 40 & $<0.21$ \\
\hline 80 & $<0.11$ \\
\hline
\end{tabular}




\subsection{Round Robin Test Chip}

The test chip used for this experiment was fabricated on the Multi-User MEMS Processes (MUMPs) ${ }^{5}$ process run 46. The design for this test chip is depicted in Figure 1. The design file (in GDS-II format) for this chip can be downloaded from the MEMS Length and Strain Calculator web site [7].

For the MUMPs, there are three mechanical layers (poly1, poly2, and a combined thickness of poly1 and poly2). Within the design shown in Figure 1, structures in these mechanical layers are specified with a "P1" (poly1), a "P2" (poly2), or a "P12" (combined poly1 and poly2).

The test chip is divided into four quadrants with measurement-specific test structures for each of the mechanical layers included in each quadrant as listed in Table 2. All test structures are provided in both 0 degree and 90 degree orientations.

Table 2. Quadrant, Measurement, and Associated Test Structures for the MEMS Round Robin Test Chip in Figure 1

\begin{tabular}{|c|l|l|}
\hline Quad & Measurement & \multicolumn{1}{|c|}{ Associated Test Structures } \\
\hline $\begin{array}{c}\text { Q1 } \\
\text { (upper } \\
\text { left) }\end{array}$ & In-plane length & $\begin{array}{l}\text { Two ends anchored: Fixed-fixed beams } \\
\text { One end anchored: Cantilevers } \\
\text { Two ends unanchored*: Rings }\end{array}$ \\
\hline $\begin{array}{c}\text { Q2 } \\
\text { (lower } \\
\text { left) }\end{array}$ & In-plane deflection & $\begin{array}{c}\text { Released part to released part: } \\
\text { Bow-ties } \\
\text { Released part to fixed location: } \\
\text { Pointers }\end{array}$ \\
\hline $\begin{array}{c}\text { Q3 } \\
\text { (upper } \\
\text { right) }\end{array}$ & Residual strain & Fixed-fixed beams \\
\hline $\begin{array}{c}\text { Q4 } \\
\text { lower } \\
\text { right) }\end{array}$ & Strain gradient & Cantilevers \\
\hline
\end{tabular}

*A structure with two ends unanchored refers to a MEMS structure that is not anchored along the direction of the measurement.

\section{Round Robin Measurement Procedure}

The procedures for measurement of in-plane length are given in subsection 3.1, the residual strain in subsection 3.2, and the strain gradient in subsection 3.3.

\subsection{In-Plane Length Measurements}

There are three classes of in-plane length test structures (given in Table 2) as determined by their end conditions. However, for the round robin, measurements were made in only the first Q1 subdivision on fixed-fixed beam test structures, which have two ends anchored, as shown in Figures 1 and 2.

The in-plane length measurements are made with an optical interferometer. Many interferometers are purchased with five magnifications $(5 \times, 10 \times, 20 \times, 40 \times$, and $80 \times)$. Therefore, for each magnification, a fixed-fixed beam is provided. The design lengths $\left(L_{\text {des }}\right)$ of $1000 \mu \mathrm{m}, 500 \mu \mathrm{m}$,

\footnotetext{
5 In this guide, commercial equipment, instruments, or processes may be indentified. This does not imply recommendation or endorsement by the National Institute of Standards and Technology (NIST), nor does it imply that the equipment, instruments, or processes are the best available for the purpose.
}

$200 \mu \mathrm{m}, 80 \mu \mathrm{m}$, and $25 \mu \mathrm{m}$, respectively, are included for each mechanical layer and for each orientation. For the round robin, the participant was informed which orientation of five poly1 fixed-fixed beams to measure in a letter accompanying the round robin test chip.

In this Q1 subdivision, two different data analysis sheets can be used. Measurements for both Data Analysis Sheet A and Data Analysis Sheet B were requested. Sheet $A$ is for in-plane length measurements when the transitional edges are facing each other. For this sheet, measurements were requested from Edges " 1 " and "2," as shown in Figures 2 and 3, using Trace "a" or "e."

Given a transitional edge, such as Edge "1" in Figures 2 and 3, the lower transitional $x$-value, $x_{\text {lower }}$, is found as follows. Going from Point "g" to Point "h," the out-ofplane $z$-values are examined one-by-one. The data points are skipped over until a $z$ value is obtained that is less than $75 \mathrm{~nm}$. (This assumes of course that the data were properly leveled with respect to the underlying layer.) This criterion may need to be modifed for peculiarities in the sample and/or the 2-D data trace being examined. The $x$ value associated with the newly found $z$ value is $x l_{\text {lower }}$, where the number " $l$ " is indicative of the specific transitional edge being examined, which in this case is Edge "1."

The upper transitional $x$-data value, $x_{\text {upper }}$, is found as follows. The $x$ values are examined one-by-one going from Point "h" to Point "g" in Figures 2 and 3. Along the upper half of the transition, the $x$ value associated with the first $z$ value, which is less than $300 \mathrm{~nm}$ from the next $z$ value, is called $x_{\text {upper }}$, or $x l_{\text {upper }}$ in this case. This criteria may need to be modifed for peculiarities in the sample and/or the 2-D data trace being examined.

If an in-plane length measurement is determined between transitional edges that face each other, such as Edges "1" and "2" in Figures 2 and 3, then the in-plane length, $L$, the minimum length, $L_{m i n}$, and the maximum length, $L_{\max }$, are calculated as follows:

$$
L=\left(L_{\min }+L_{\max }\right) / 2
$$

where

$$
L_{\text {min }}=x 2_{\text {min }}-x 1_{\text {min }}
$$

and

$$
L_{\max }=x 2_{\max }-x 1_{\max } .
$$

The "min" subscript refers to the transitional $x$ value (xlower or $x_{\text {upper }}$ ) that yields a minimum length. The "max" subscript refers to the transitional $x$ value ( $x_{\text {lower }}$ or $x_{\text {upper }}$ ) that yields a maximum length.

Data Analysis Sheet B is for in-plane length measurements when the transitional edges are oriented in the same direction. For this sheet, measurements are requested from Edges " 1 " and "5," as shown in Figures 2 and 3, using Trace "a" or "e." The design lengths $\left(L_{d e s}\right)$ for 
these measurements are $1035 \mu \mathrm{m}, 535 \mu \mathrm{m}, 235 \mu \mathrm{m}$, $115 \mu \mathrm{m}$, and $60 \mu \mathrm{m}$. The equations for $L_{\min }$ and $L_{\max }$ are

$$
L_{\text {min }}=L-2 * \text { sep }
$$

and

$$
L_{\max }=L+2 * \operatorname{sep}
$$

where

$$
L=x 2_{\text {lower }}-x 1_{\text {lower }}
$$

or

$$
L=x 2_{\text {upper }}-x 1_{\text {upper }}
$$

as determined from the 2-D data trace being examined, and sep is the average calibrated separation between two interferometric pixels.

Following ASTM E 2244, the raw, uncalibrated measurements were recorded on Data Analysis Sheet A or $\mathrm{B}$, as appropriate. A summary of the round robin results from Data Sheets A and B is presented in subsection 5.1.

\subsection{Residual Strain Measurements}

In $\mathrm{Q} 3$, the measurements for residual strain, $\varepsilon_{r}$, are made. Fixed-fixed beams are provided for this purpose as shown in Figures 1 and 2. The fixed-fixed beam design lengths are $400 \mu \mathrm{m}, 450 \mu \mathrm{m}, 500 \mu \mathrm{m}, 550 \mu \mathrm{m}, 600 \mu \mathrm{m}$, $650 \mu \mathrm{m}, 700 \mu \mathrm{m}, 750 \mu \mathrm{m}$, and $800 \mu \mathrm{m}$. There are three fixed-fixed beams designed at each length. Thus, there are twenty-seven fixed-fixed beams for each mechanical layer and for each orientation.

Measurements from two poly1 fixed-fixed beams on the MUMPs chip were requested using Data Analysis Sheet G. Measurements are requested from Edges "1" and "2," as shown in Figure 2, using Trace "a" or "e," depicted in Figure 3. Data points along the fixed-fixed beam, as shown in Figure 5, namely $\left(x_{1 F}, z_{1 F}\right),\left(x_{2 F}, z_{2 F}\right),\left(x_{3 F}=x_{1 S}\right.$, $\left.z_{3 F}=z_{1 S}\right),\left(x_{2 S}, z_{2 S}\right)$, and $\left(x_{3 S}, z_{3 S}\right)$, are also requested from Traces "b," "c," and "d."

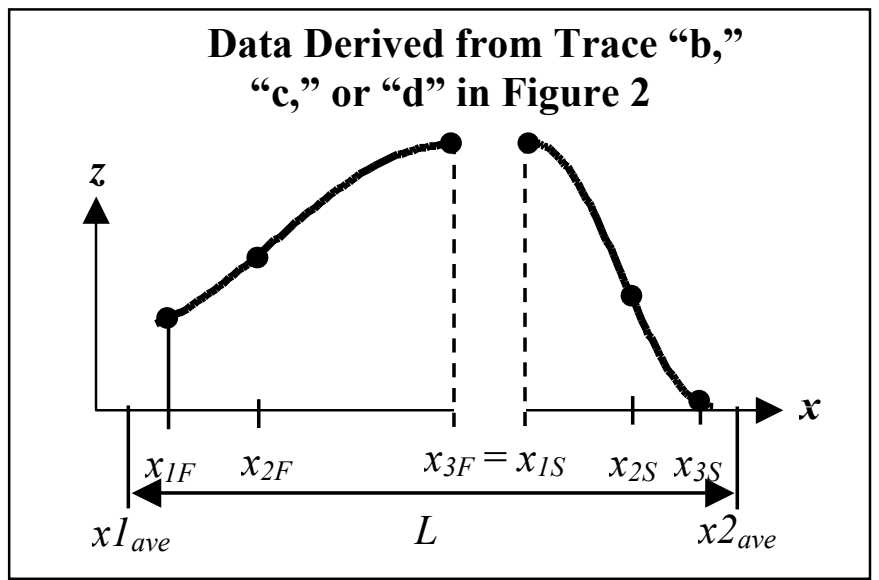

Figure 5. Two data sets derived from an abbreviated data trace along a fixed-fixed beam. The vertical scale in the figure above has been exaggerated.
Following ASTM E 2245 for measuring residual strain, the raw, uncalibrated measurements were recorded on Data Analysis Sheet G. A summary of the round robin results from these data analysis sheets is presented in subsection 5.2 .

\subsection{Strain Gradient Measurements}

In Q4, the measurements for strain gradient, $s_{g}$, are made. Cantilevers are provided for this purpose as shown in Figures 1 and 6. The cantilever design lengths are 400 $\mu \mathrm{m}, 450 \mu \mathrm{m}, 500 \mu \mathrm{m}, 550 \mu \mathrm{m}, 600 \mu \mathrm{m}, 650 \mu \mathrm{m}, 700 \mu \mathrm{m}$, $750 \mu \mathrm{m}$, and $800 \mu \mathrm{m}$. There are three cantilevers designed at each length. Thus, there are twenty-seven cantilevers for each mechanical layer and for each orientation.

Measurements from two poly1 cantilevers on the MUMPs chip were requested using Data Analysis Sheet H. Measurements were requested from Edge "1," as shown in Figure 6, using Trace "a" or "e," depicted in Figure 7. Data points along the cantilever, as shown in Figure 8, namely $\left(x_{1}, z_{1}\right),\left(x_{2}, z_{2}\right)$, and $\left(x_{3}, z_{3}\right)$, were also requested from Traces "b," "c," and "d."

Following ASTM E 2246 for strain gradient measurements, the raw, uncalibrated measurements were recorded on Data Analysis Sheet H. A summary of the round robin results from these data analysis sheets is presented in subsection 5.3.

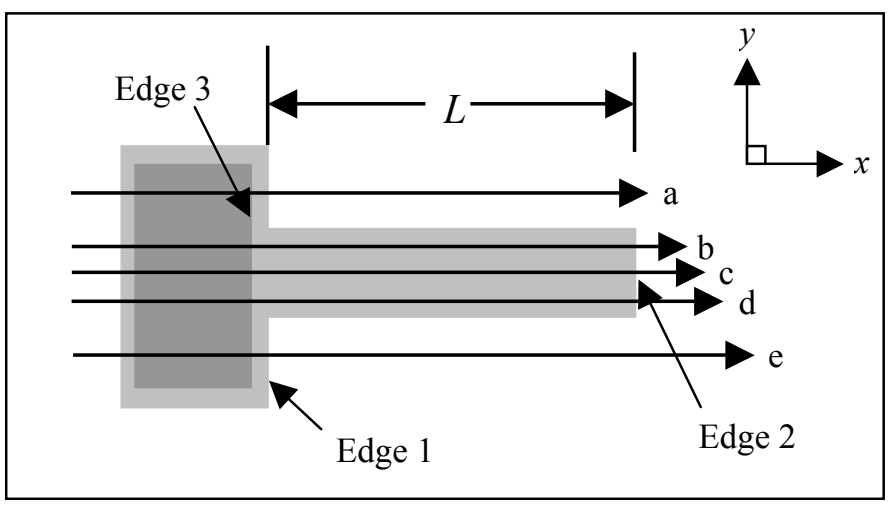

Figure 6. Top view of a cantilever test structure.

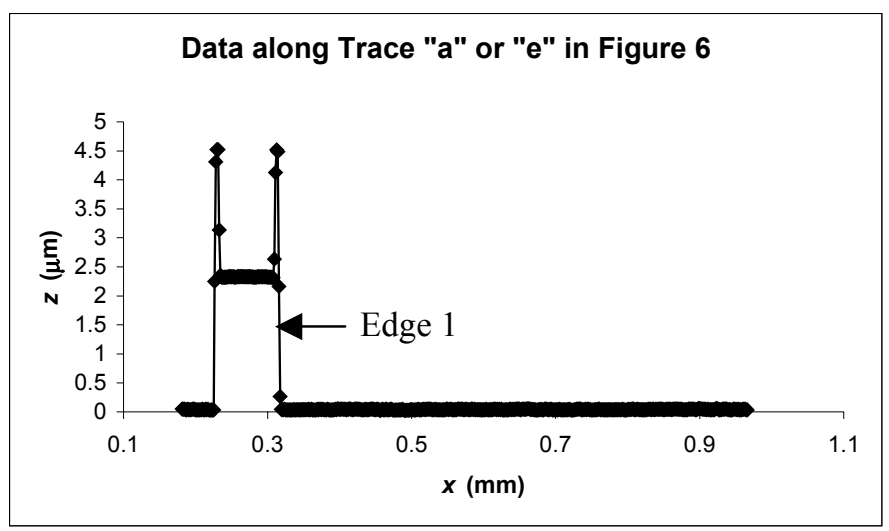

Figure 7. An example of a 2-D data trace adjacent to a cantilever. 


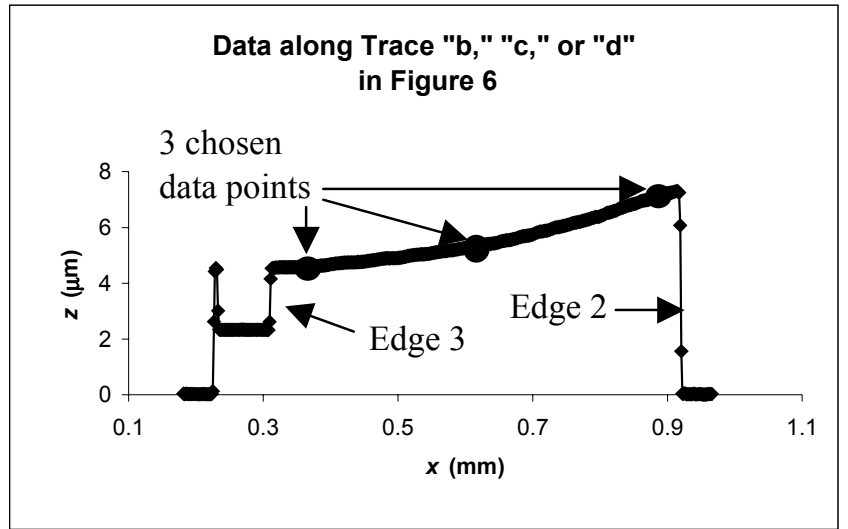

Figure 8. A 2-D data trace used to find three data points.

\section{Uncertainty Calculations}

In this section, the equations used to determine the values of the combined standard uncertainty [4], $u_{c}$, are presented. The first subsection presents the basic combined standard uncertainty equation, and the second through fourth subsections present the more specific uncertainty equations for the in-plane length measurements, the residual strain measurements, and the strain gradient measurements, respectively.

\subsection{The Combined Standard Uncertainty Equation}

The combined standard uncertainty [4] is comparable to the estimated standard deviation of the result. It is equal to the square root of the sum of the squares of the uncertainty components.

For the case of three sources of uncertainty, the uncertainty equation would be as follows:

$$
u_{c}=\sqrt{u_{1}^{2}+u_{2}^{2}+u_{3}^{2}}
$$

where $u_{1}$ is the uncertainty component due to the first source of uncertainty, $u_{2}$ is the uncertainty component due to the second source of uncertainty, and $u_{3}$ is due to the third source of uncertainty. Additional terms may be added under the square root sign in (8) for additional sources of uncertainty.

\subsection{In-Plane Length Uncertainty Calculations}

In this subsection, a combined standard uncertainty equation is presented for use with in-plane length measurements. For these measurements, three sources of uncertainty are identified with all other sources considered negligible. The three sources of uncertainty are the uncertainty of the in-plane length measurement $\left(u_{L}\right)$, the uncertainty of the calibration of the interferometer in the $x$ direction $\left(u_{x c a l}\right)$, and the uncertainty due to the resolution of the interferometer in the $x$-direction $\left(u_{x r e s}\right)$. As such, the combined standard uncertainty equation [8] can be written as follows:

$$
u_{c}=\sqrt{u_{L}{ }^{2}+u_{x c a l}{ }^{2}+u_{x r e s}{ }^{2}} \text {. }
$$

The uncertainty of $u_{L}$ is determined from the minimum and maximum length values (namely, $L_{\min }$ and $L_{\max }$ ) as given in (2) and (3), respectively, or (4) and (5), respectively. With $99.7 \%$ confidence, assuming a Gausssian distribution (and assuming $u_{x c a l}$ and $u_{x r e s}$ equal zero), the value for $L$ lies between $L_{\min }$ and $L_{\max }$. Therefore, $u_{L}$ is calculated as follows:

$$
u_{L}=\left(L_{\max }-L_{\min }\right) / 6 \text {. }
$$

If the transitional edges defining the in-plane length measurement face the same direction and have similar slopes and magnitudes, the equations for $L_{\min }$ and $L_{\max }$ are given by (4) and (5), and (10) can be reduced to the following equation:

$$
u_{L}=2 * \operatorname{sep} / 3
$$

where sep is the average calibrated separation between two interferometric pixels.

The uncertainty equation for $u_{x c a l}$ can be found from the minumum and maximum length values (namely, $L_{\text {minxcal }}$ and $L_{\text {maxxcal }}$ ) as determined from the mininum and maximum calibration factors (namely, $c a l_{x \min }$ and $c a l_{x \max }$ ). Therefore,

$$
L_{\text {minxcal }}=L^{*} \operatorname{cal}_{\text {xmin }} / c a l_{x}
$$

and

$$
L_{\text {maxxcal }}=L^{*} c_{\text {amax }} / l_{\text {mal }}
$$

where

$$
\begin{aligned}
& c a l_{x \min }=c a l_{x}-3 * \sigma_{x c a l} / \text { inter }_{x}, \\
& \text { cal }_{x \max }=c a l_{x}+3 * \sigma_{x c a l} / \text { inter }_{x},
\end{aligned}
$$

and

$$
\operatorname{cal}_{x}=\text { ruler }_{x} / \text { inter }_{x}
$$

with $L$ given in (1), (6), or (7). Here, $c a l_{x}$ is defined as the $x$-calibration factor of the interferometer for the given combination of lenses; ruler $x_{x}$ is defined as the interferometer's maximum field of view in the $x$-direction for the given combination of lenses as measured with a $10 \mu \mathrm{m}$ grid (or finer grid) ruler; $\sigma_{x c a l}$ is the standard deviation in a ruler measurement in the interferometer's $x$ direction for the given combination of lenses; and inter $r_{x}$ is the interferometer's maximum field of view in the $x$ direction for the given combination of lenses. With $99.7 \%$ confidence assuming a Gaussian distribution (and assuming $u_{L}$ and $u_{x r e s}$ equal zero), the value for $L$ lies between $L_{\text {minxcal }}$ and $L_{\text {maxxcal }}$. Therefore, $u_{x c a l}$ is calculated as follows: 


$$
\begin{aligned}
u_{x c a l} & =\left(L_{\text {maxxcal }}-L_{\text {minxcal }}\right) / 6 \\
& =\left(L^{*} \text { cal }_{x \max }-L^{*} \text { cal }_{x \min }\right) /\left(6 * 6 a l_{x}\right) . \\
& =\left(\sigma_{x c a l} * L\right) /\left(\text { inter }_{x} * c a l_{x}\right)
\end{aligned}
$$

And lastly, the uncertainty equation for $u_{x r e s}$, is found from the minimum and maximum length values (namely, $L_{\text {minres }}$ and $L_{\text {maxres }}$ ) defined as follows:

$$
L_{\text {minres }}=L-x_{\text {res }}
$$

and

$$
L_{\text {maxres }}=L+x_{\text {res }}
$$

where $x_{\text {res }}$ is the resolution of the interferometer in the $x$ direction. Assuming a uniform distribution (and assuming $u_{L}$ and $u_{x c a l}$ equal zero), the value for $L$ lies between $L_{\text {minres }}$ and $L_{\text {maxres. }}$. Therefore, $u_{x r e s}$ is calculated as follows:

$$
u_{\text {xres }}=\left(L_{\text {maxres }}-L_{\text {minres }}\right) /(2 \sqrt{3})=x_{\text {res }} / 1.732 \text {. }
$$

\subsection{Residual Strain Uncertainty Calculations}

In this subsection, a combined standard uncertainty equation is presented for use with residual strain measurements. Eight sources of uncertainty are indentified with all other sources of uncertainty considered negligible. Towards the end of this subsection, the uncertainty equation will be expanded to include twelve sources of uncertainty. Knowledge of the additional sources of uncertainty can be a tremendous benefit when taking and analyzing other interferometeric measurements (such as, 80 $\mu \mathrm{m}$ step heights).

The residual strain combined standard uncertainty equation (as calculated in Data Analysis Sheet G [7] and in ASTM Test Method E 2245-05 [9]) with eight sources of uncertainty is as follows:

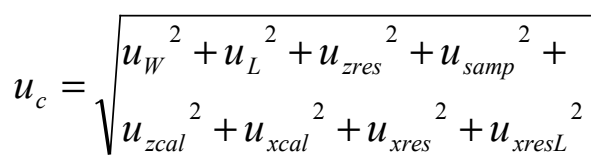

where $u_{W}$ is the uncertainty due to variations across the width of the beam, $u_{z r e s}$ is the uncertainty due to the resolution of the interferometer in the $z$-direction, $u_{\text {samp }}$ is the uncertainty due to the sample's peak-to-valley surface roughness as measured with the interferometer, $u_{z c a l}$ is the uncertainty of the calibration in the $z$-direction, and $u_{x r e s L}$ is the uncertainty due to the resolution of the interferometer in the $x$-direction as pertains to the in-plane length measurement. Calculations for each uncertainty component will be presented in sequence, with Table 3 giving a brief tabular summary of how each uncertainty component is obtained. This table can be referenced as each component is discussed.

Table 3. Determination of the Residual Strain Uncertainty Components*

\begin{tabular}{|l|c|c|c|c|}
\hline $\begin{array}{l}\text { Uncertainty } \\
\text { Component }\end{array}$ & $\begin{array}{c}\text { Varied } \\
\text { From }\end{array}$ & $\begin{array}{c}\text { Varied } \\
\text { To }\end{array}$ & $\begin{array}{c}\text { How } \\
\text { Varied } \\
* *\end{array}$ & $\begin{array}{c}\text { G } \\
\text { or } \\
\mathbf{u} \\
* * *\end{array}$ \\
\hline 1. $\boldsymbol{u}_{\boldsymbol{W}}$ & $\begin{array}{c}\text { max } \varepsilon_{r} \text { value } \\
\text { from Trace b, } \\
\mathrm{c}, \text { and d }\end{array}$ & $\begin{array}{c}\text { min } \varepsilon_{r} \text { value } \\
\text { from Trace } \mathrm{b}, \\
\mathrm{c}, \text { and d }\end{array}$ & - & $\mathrm{u}$ \\
\hline 2. $\boldsymbol{u}_{\boldsymbol{L}}$ & with $L=L_{\text {max }}$ & with $L=L_{\text {min }}$ & - & $\mathrm{G}$ \\
\hline 3. $\boldsymbol{u}_{\text {zres }}$ & $+(1 / 2) z_{\text {res }}$ & $-(1 / 2) z_{\text {res }}$ & 4 & $\mathrm{u}$ \\
\hline 4. $\boldsymbol{u}_{\text {samp }}$ & $+3 \sigma_{\text {samp }}$ & $-3 \sigma_{\text {samp }}$ & 4 & $\mathrm{G}$ \\
\hline 5. $\boldsymbol{u}_{\text {zcal }}$ & $+d$ & $-d$ & 5 & $\mathrm{G}$ \\
\hline 6. $\boldsymbol{u}_{\text {xcal }}$ & with & with & - & $\mathrm{G}$ \\
\hline 7. $\boldsymbol{u}_{\text {xres }}$ & $+(1 / 2) x_{\text {res }}$ & $-(1 / 2) x_{\text {res }}$ & 6 & $\mathrm{u}$ \\
\hline 8. $\boldsymbol{u}_{\text {xres }}$ & $+(1 / 2) x_{\text {res }}$ & $-(1 / 2) x_{\text {res }}$ & 7 & $\mathrm{u}$ \\
\hline 9. $\boldsymbol{u}_{\text {Rave }}$ & $+3 \sigma_{\text {Rave }}$ & $-3 \sigma_{\text {Rave }}$ & 4 & $\mathrm{G}$ \\
\hline 10. $\boldsymbol{u}_{\text {noise }}$ & $+3 \sigma_{\text {noise }}$ & $-3 \sigma_{\text {noise }}$ & 4 & $\mathrm{G}$ \\
\hline 11. $\boldsymbol{u}_{\text {cert }}$ & $+d$ & $-d$ & 5 & $\mathrm{G}$ \\
\hline 12. $\boldsymbol{u}_{\text {repeat }}$ & $+d$ & $-d$ & 5 & $\mathrm{u}$ \\
\hline 13. $\boldsymbol{u}_{\text {drift }}$ & $+d$ & $-d$ & 5 & $\mathrm{u}$ \\
\hline 14. $\boldsymbol{u}_{\text {linear }}$ & $+d$ & $-d$ & 5 & $\mathrm{u}$ \\
\hline
\end{tabular}

* In this table, $d=3\left(z_{x x}-z_{1 F}\right) \sigma_{z c a l} /$ cert to determine $u_{z c a l}$ where $z_{x x}$ is the appropriate column heading in Table $5, d=3\left(z_{x x}-z_{1 F}\right) \sigma_{\text {cert }} /$ cert to determine $u_{\text {cert }}, d=\left(z_{x x}-z_{l F}\right) z_{\text {repeat }} /\left(2 * \mu_{6}\right)$ to determine $u_{\text {repeat }}, d=\left(z_{x x}-z_{l F}\right) z_{\text {drift }} /(2 * \mu)$ to determine $u_{\text {drift }}$, and $d=z_{\text {linear }}$ to determine $u_{\text {linear }}$.

** The entries in this column specify the table number where the input variations can be found, if applicable.

*** "G" indicates a Gaussian distribution and " $u$ " indicates a uniform distribution.

The uncertainty equation for $u_{W}$ is found using the residual strain results from at least two data traces across the width of the beam. The two extreme residual strain values ( $\varepsilon_{r \text {-low }}$ and $\left.\varepsilon_{r \text {-high }}\right)$ are subtracted and divided by two as follows:

$$
w_{1 / 2}=\left(\varepsilon_{r-h i g h}-\varepsilon_{r-l o w}\right) / 2
$$

to determine the half width of the interval, $w_{1 / 2}$. Assuming a uniform probability distribution, $u_{W}$ is calculated using the following formula:

$$
u_{W}=w_{1 / 2} / 1.732
$$

The uncertainty equation for $u_{L}$ is found after calculating the residual strain in two different ways. First, the residual strain is found assuming that $L_{\min }$ is the in- 
plane length of the fixed-fixed beam and second, assuming that $L_{\max }$ is the in-plane length of the fixed-fixed beam. Both of these assumptions will precipitate a recalculation of the curved length of the fixed-fixed beam. Then, $w_{1 / 2}$ is calculated using (22), and $u_{L}$ is calculated assuming a Gaussian distribution with the following equation:

$$
u_{L}=w_{1 / 2} / 3
$$

The uncertainty equation for $u_{z r e s}$ is found from the residual strain calculations using the different sets of inputs given in Table 4. Here, the inputed $z$-values along the top of the beam are varied plus or minus half $z_{\text {res }}$, where $z_{\text {res }}$ is the resolution of the interferometer in the $z$-direction. The two residual strain values $\left(\varepsilon_{r-l o w}\right.$ and $\left.\varepsilon_{r \text {-high }}\right)$ are identified. Then, $w_{1 / 2}$ is calculated using (22), followed by the determination of $u_{\text {zres }}$, assuming a uniform distribution, using the following equation:

$$
u_{z r e s}=w_{1 / 2} / 1.732
$$

The uncertainty equation for $u_{\text {samp }}$ is found from a determination of $R_{\text {tave }}$, the peak-to-valley roughness of a flat and leveled surface of the sample material calculated to be the average of three or more measurements, each measurement of which is taken from a different 2-D data trace. Then, the standard deviation, $\sigma_{\text {samp, }}$, of this measurement is calculated to be one-sixth the value of $R_{\text {tave }}$. The data points obtained along the top of the beam are then varied as specified in Table 4 (with $d=3 \sigma_{\text {samp }}$ ) and the residual strain determined for the different sets of inputs. Given the resulting residual strain values, $\varepsilon_{r-l o w}$ and $\varepsilon_{r \text {-high }}$ are identified. The interval from $\varepsilon_{r \text {-low }}$ to $\varepsilon_{r \text {-high }}$ is assumed to encompass $99 \%$ of the measurements. Then, $w_{1 / 2}$ is calculated using (22), followed by the determination

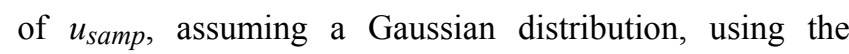
following equation:

$$
u_{\text {samp }}=w_{1 / 2} / 3
$$

The method of calibration of the interferometer in the $z$ direction affects the determination of the uncertainty component $u_{z c a l}$. (Later in this subsection, using a different calibration method, $u_{z c a l}$ is divided into four separate components.) To determine $u_{z c a l}$, the $z$-calibration of the interferometer is done as follows: twelve step height measurements are taken on the double-sided step height standard with six measurements taken before the data session and six after the data session. Three of the six measurements are spread out evenly along one side of the step height standard, and the other three are spread out evenly along the other side of the step height standard with one 3-D data set obtained for each measurement. The $z$ - calibration factor $\left(\mathrm{cal}_{z}\right)$ is determined by dividing the certified value of the step-height standard (cert) by the mean value of the twelve measurements $(\mu)$. All of the data values obtained during the data session are multiplied by $\mathrm{Cal}_{z}$ to obtain calibrated $z$-data values.

Table 4. Seven Sets of Inputs for Residual Strain Calculations to Determine $u_{\text {zres }}, u_{\text {samp }}, u_{\text {Rave }}$, and $u_{\text {noise }} *$

\begin{tabular}{|c|c|c|c|c|c|}
\hline & $\boldsymbol{z}_{\mathbf{1 F}}$ & $\boldsymbol{z}_{2 \boldsymbol{F}}$ & $\boldsymbol{z}_{3 F^{-}}=\boldsymbol{z}_{1 S}$ & $\boldsymbol{z}_{2 S}$ & $\boldsymbol{z}_{3 S}$ \\
\hline $\mathbf{1}$ & $z_{1 F}$ & $z_{2 F}$ & $z_{3 F}$ & $z_{2 S}$ & $z_{3 S}$ \\
\hline $\mathbf{2}$ & $z_{1 F}+d$ & $z_{2 F}$ & $z_{3 F}-d$ & $z_{2 S}$ & $z_{3 S}+d$ \\
\hline $\mathbf{3}$ & $z_{1 F}-d$ & $z_{2 F}$ & $z_{3 F}+d$ & $z_{2 S}$ & $z_{3 S}-d$ \\
\hline $\mathbf{4}$ & $z_{1 F}+d$ & $z_{2 F+d}$ & $z_{3 F}-d$ & $z_{2 S}+d$ & $z_{3 S}+d$ \\
\hline $\mathbf{5}$ & $z_{1 F}+d$ & $z_{2 F}-d$ & $z_{3 F}-d$ & $z_{2 S}-d$ & $z_{3 S}+d$ \\
\hline $\mathbf{6}$ & $z_{1 F}-d$ & $z_{2 F+d}$ & $z_{3 F}+d$ & $z_{2 S+d}$ & $z_{3 S}-d$ \\
\hline $\mathbf{7}$ & $z_{1 F}-d$ & $z_{2 F}-d$ & $z_{3 F}+d$ & $z_{2 S}-d$ & $z_{3 S}-d$ \\
\hline
\end{tabular}

* In this table, $d=(1 / 2) z_{\text {res }}$ to determine $u_{\text {zres }}, d=3 \sigma_{\text {samp }}$ to determine $u_{\text {samp }}$, $d=3 \sigma_{\text {Rave }}$ to determine $u_{\text {Rave }}$, and $d=3 \sigma_{\text {noise }}$ to deterimine $u_{\text {noise }}$.

In view of the above method of calibration, the uncertainty equation for $u_{z c a l}$ is found from the residual strain calculations using the three different sets of inputs given in Table 5 [with $d=3\left(z_{x x}-z_{l F}\right) \sigma_{z c a l} /$ cert]. Here, $\sigma_{z c a l}$, the standard deviation of the twelve step height measurements on the double-sided step height standard, is assumed to scale linearly with height. Due to the fact that the difference in height being measured for residual strain measurements is small, $u_{z c a l}$ is almost negligible. Also, due to the method of calibration and other factors, $u_{z c a l}$ is very much considered an estimate.

Given the three different residual strain values for the inputs specified in Table $5, \varepsilon_{r \text {-low }}$ and $\varepsilon_{r \text {-high }}$ are identified. The interval from $\varepsilon_{r-l o w}$ to $\varepsilon_{r-h i g h}$ is assumed to encompass $99 \%$ of the measurements. Then, $w_{1 / 2}$ is calculated using (22), followed by the determination of $u_{z c a l}$, assuming a Gaussian distribution, using the following equation:

$$
u_{z c a l}=w_{1 / 2} / 3
$$

\begin{tabular}{|c|c|c|c|c|c|}
\hline \multicolumn{6}{|c|}{$u_{\text {drift, }}$ and $u_{\text {linear }}{ }^{*}$} \\
\hline & $z_{1 F}$ & $z_{2 F}$ & $z_{3 F}=z_{1 S}$ & $z_{2 S}$ & $z 3 S$ \\
\hline 1 & $\boldsymbol{z}_{1 F}$ & $\boldsymbol{z}_{2 F}$ & $\boldsymbol{z}_{3 F}$ & $\boldsymbol{z}_{2 S}$ & $\boldsymbol{z}_{3 S}$ \\
\hline 2 & $z_{1 F}$ & $z_{2 F}+d$ & $z_{3 F}+d$ & $z_{2 S}+d$ & $z_{3 S}+d$ \\
\hline 3 & $z_{1 F}$ & $z_{2 F}-d$ & $z_{3 F}-d$ & $z_{2 S}-d$ & $z_{3 S}-d$ \\
\hline
\end{tabular}

Table 5. Three Sets of Inputs for Residual Strain Calculations to Determine $u_{z c a l}, u_{c e r t}, u_{\text {repeat }}$,

* In this table, $d=3\left(z_{x x}-z_{I F}\right) \sigma_{z c a l} /$ cert to determine $u_{z c a l}$ where $z_{x x}$ is the column heading, $d=3\left(z_{x x}-z_{l F}\right) \sigma_{\text {cert }} /$ cert to determine $u_{\text {cert }}$, $d=\left(z_{x x}-z_{l F}\right) z_{\text {repeat }} /\left(2^{*} \mu_{6}\right)$ to determine $u_{\text {repeat }}, \quad d=\left(z_{x x}-z_{l F}\right) z_{\text {drift }} /\left(2^{*} \mu\right)$ to determine $u_{\text {driftit }}$, and $d=z_{\text {linear }}$ to determine $u_{\text {linear }}$. 
The uncertainty equation for $u_{x c a l}$ is found by finding the residual strain value with $c a l_{x \min }$ from (14) as the $x$ calibration factor and then finding the residual strain value with cal $_{x \max }$ from (15) as the $x$-calibration factor. The two residual strain values $\left(\varepsilon_{r \text {-low }}\right.$ and $\left.\varepsilon_{r \text {-high }}\right)$ are identified. Then, $w_{1 / 2}$ is calculated using (22), followed by the determination of $u_{x c a l}$, assuming a Gaussian distribution, using the following equation:

$$
u_{x c a l}=w_{1 / 2} / 3
$$

The uncertainty equation for $u_{x r e s}$ is found from the residual strain calculations using the seven different sets of inputs given in Table 6 . Here, the inputted $x$-values along the top of the beam are varied plus or minus half $x_{\text {res }}$. The two residual strain values $\left(\varepsilon_{r \text {-low }}\right.$ and $\left.\varepsilon_{r \text {-high }}\right)$ are identified. Then, $w_{1 / 2}$ is calculated using (22), followed by the determination of $u_{x r e s}$, assuming a uniform distribution, using the following equation:

$$
u_{x r e s}=w_{1 / 2} / 1.732 \text {. }
$$

Table 6. Seven Sets of Inputs for Residual Strain Calculations to Determine $u_{\text {xres }}{ }^{*}$

\begin{tabular}{|c|c|c|c|c|c|}
\hline & $x_{1 F}$ & $x_{2 F}$ & $x_{3 F}=x_{1 S}$ & $x_{2 S}$ & $x_{3 S}$ \\
\hline $\mathbf{1}$ & $x_{1 F}$ & $x_{2 F}$ & $x_{3 F}$ & $x_{2 S}$ & $x_{3 S}$ \\
\hline $\mathbf{2}$ & $x_{1 F}+d$ & $x_{2 F}$ & $x_{3 F}$ & $x_{2 S}$ & $x_{3 S}-d$ \\
\hline $\mathbf{3}$ & $x_{1 F}-d$ & $x_{2 F}$ & $x_{3 F}$ & $x_{2 S}$ & $x_{3 S}+d$ \\
\hline $\mathbf{4}$ & $x_{1 F}+d$ & $x_{2 F}+d$ & $x_{3 F}$ & $x_{2 S}-d$ & $x_{3 S}-d$ \\
\hline $\mathbf{5}$ & $x_{1 F}+d$ & $x_{2 F}-d$ & $x_{3 F}$ & $x_{2 S}+d$ & $x_{3 S}-d$ \\
\hline $\mathbf{6}$ & $x_{1 F}-d$ & $x_{2 F}+d$ & $x_{3 F}$ & $x_{2 S}-d$ & $x_{3 S}+d$ \\
\hline $\mathbf{7}$ & $x_{1 F}-d$ & $x_{2 F}-d$ & $x_{3 F}$ & $x_{2 S}+d$ & $x_{3 S}+d$ \\
\hline
\end{tabular}

* In this table, $d=(1 / 2) x_{\text {res }}$.

The uncertainty equation for $u_{x r e s L}$ is found from the residual strain calculations from the two sets of inputs given in Table 7 for $x 1_{\max }, x 1_{\min }, x 2_{\min }$, and $x 2_{\max }$. In this table, $x l_{\text {upper }}$ is the original value for $x l_{\max }, x l_{\text {lower }}$ is the original value for $x 1_{\min }, x 2_{\text {lower }}$ is the original value for $x 2_{\min }$, and $x 2_{\text {upper }}$ is the original value for $x 2_{\max }$. As can be seen in this table, the minimum and maximum in-plane length endpoints are varied plus or minus half $x_{\text {res }}$. Then, $\varepsilon_{r-\text { low }}$ and $\varepsilon_{r \text {-high }}$ are determined and $w_{1 / 2}$ is calculated using (22), followed by the determination of $u_{x r e s}$, assuming a uniform distribution, using the following equation:

$$
u_{x r e s L}=w_{1 / 2} / 1.732 \text {. }
$$

Table 7. Two Sets of Inputs for Residual Strain

\begin{tabular}{|l|l|l|}
\hline & \multicolumn{3}{|c|}{ Calculations to Determine $u_{\text {xres }}$} \\
\hline $\boldsymbol{x} \boldsymbol{1}_{\max }$ & $x 1_{\text {upper }}-(1 / 2) x_{\text {res }}$ & $x 1_{\text {upper }}+(1 / 2) x_{\text {res }}$ \\
\hline $\boldsymbol{x} \boldsymbol{1}_{\min }$ & $x 1_{\text {lower }}-(1 / 2) x_{\text {res }}$ & $x 1_{\text {lower }}+(1 / 2) x_{\text {res }}$ \\
\hline $\boldsymbol{x} \boldsymbol{2}_{\min }$ & $x 2_{\text {lower }}+(1 / 2) x_{\text {res }}$ & $x 2_{\text {lower }}-(1 / 2) x_{\text {res }}$ \\
\hline $\boldsymbol{x} \boldsymbol{2}_{\max }$ & $x 2_{\text {upper }}+(1 / 2) x_{\text {res }}$ & $x 2_{\text {upper }}-(1 / 2) x_{\text {res }}$ \\
\hline
\end{tabular}

The combined standard uncertainty equation for residual strain measurements (as calculated in Data Analysis Sheet I [7]) with twelve uncertainty components is as follows:

$$
u_{c}=\sqrt{\begin{array}{l}
u_{W}{ }^{2}+u_{L}{ }^{2}+u_{\text {zres }}{ }^{2}+ \\
u_{\text {xcal }}{ }^{2}+u_{\text {xres }}{ }^{2}+u_{\text {xresL }}{ }^{2}+ \\
u_{\text {Rave }}{ }^{2}+u_{\text {noise }}{ }^{2}+u_{\text {cert }}{ }^{2}+ \\
u_{\text {repeat }}{ }^{2}+u_{\text {drift }}{ }^{2}+u_{\text {linear }}{ }^{2}
\end{array}}
$$

where $u_{\text {Rave }}$ is the uncertainty of the measurement due to the sample's surface roughness, $u_{\text {noise }}$ is the uncertainty of the measurement due to interferometric noise, $u_{c e r t}$ is the component in the combined standard uncertainty calculation that is due to the uncertainty of the value of the step-height standard, $u_{\text {repeat }}$ is the uncertainty of a measurement due to the repeatability of a measurement, $u_{\text {drift }}$ is the uncertainty of a measurement due to the amount of drift during the data session, and $u_{\text {linear }}$ is the uncertainty of a measurement due to the deviation from linearity of the data scan. In the above equation, the uncertainty components $u_{\text {Rave }}$ and $u_{\text {noise }}$ replace the previous component $u_{\text {samp. }}$. Also, the uncertainty components $u_{\text {cert }}, u_{\text {repeat }}, u_{\text {drift }}$, and $u_{\text {linear }}$ replace the previous component $u_{\text {zcal }}$.

As mentioned in the previous paragraph, $u_{\text {samp }}$ is now replaced with $u_{\text {Rave }}$ and $u_{\text {noise }} . R_{\text {tave }}$ was the measurement used to obtain $\sigma_{\text {samp }}$. Now, $R_{\text {tave }}$ is being divided into $R_{\text {ave }}$ for the determination of $u_{\text {Rave }}$ and $R_{\text {tave }}$ minus $R_{\text {ave }}$ for the determination of $u_{\text {noise }} . R_{\text {ave }}$ is defined as the surface roughness of a flat and leveled surface of the sample material calculated to be the average of three or more measurements, each measurement of which is taken from a different 2-D data trace.

The uncertainty equation for $u_{\text {Rave }}$ is found from a determination of $\sigma_{\text {Rave }}$, where $\sigma_{\text {Rave }}$ is calculated to be onesixth the value of $R_{\text {ave }}$. The data points obtained along the top of the beam are then varied as specified in Table 4 (with $d=3 \sigma_{\text {Rave }}$ ) and the residual strain determined for the different sets of inputs. The two residaul strain values $\left(\varepsilon_{r-}\right.$ low and $\left.\varepsilon_{r \text {-high }}\right)$ are then identified. The interval from $\varepsilon_{r-l o w}$ to $\varepsilon_{r-h i g h}$ is assumed to encompass $99 \%$ of the measurements. Then, $w_{1 / 2}$ is calculated using (22), followed by the determination of $u_{\text {Rave, assuming a }}$ Gaussian distribution, using the following equation: 


$$
u_{\text {Rave }}=w_{1 / 2} / 3 .
$$

The uncertainty equation for $u_{\text {noise }}$ is found from a determination of $\sigma_{\text {noise, }}$, where $\sigma_{\text {noise }}$ is the standard deviation of the noise measurement, calculated to be onesixth the value of $R_{\text {tave }}$ minus $R_{\text {ave }}$. The data points obtained along the top of the beam are then varied as specified in Table 4 (with $d=3 \sigma_{\text {noise }}$ ) and the residual strain determined for the different sets of inputs. The two residual strain values $\left(\varepsilon_{r-l o w}\right.$ and $\left.\varepsilon_{r \text {-high }}\right)$ are then identified. The interval from $\varepsilon_{r-\text {-low }}$ to $\varepsilon_{r \text {-high }}$ is assumed to encompass $99 \%$ of the measurements. Then, $w_{1 / 2}$ is calculated using (22), followed by the determination of $u_{\text {noise }}$, assuming a Gaussian distribution, using the following equation:

$$
u_{\text {noise }}=w_{1 / 2} / 3
$$

To use the uncertainty equation in (31), the calibration is done differently. Instead of the method presented earlier in this subsection, six measurements should be taken at the same location on the step height standard before the data session and six measurements taken at this same location after the data session with the average of these twelve measurements being called the mean, or $\mu$. Then, $c a l_{z}$ is calculated to be cert divided by $\mu$, and all the data values obtained during the data session are multiplied by $\mathrm{cal}_{z}$ to obtain calibrated $z$-data values. If this is done, the previous component, $u_{z c a l}$, gets replaced with $u_{\text {cert }}, u_{\text {repeat }}, u_{\text {drift }}$, and $u_{\text {linear }}$ to be described next.

The uncertainty equation for $u_{\text {cert }}$ is found from the residual strain calculations using the inputs in Table 5 [with $d=3\left(z_{x x}-z_{l F}\right) \sigma_{\text {cert }} /$ cert where $\sigma_{\text {cert }}$ is the certified one sigma uncertainty of the certified step height standard]. As with $\sigma_{z c a l}, \sigma_{c e r t}$ is assumed to scale linearly with height. Given the three different residual strain values for the inputs specified in Table 5, $\varepsilon_{r-l o w}$ and $\varepsilon_{r-h i g h}$ are identified. The interval from $\varepsilon_{r-l o w}$ to $\varepsilon_{r-h i g h}$ is assumed to encompass $99 \%$ of the measurements. Then, $w_{1 / 2}$ is calculated using (22), followed by the determination of $u_{\text {cert }}$, assuming a Gaussian distribution, using the following equation:

$$
u_{c e r t}=w_{1 / 2} / 3 \text {. }
$$

The uncertainty equation for $u_{\text {repeat }}$ is found from the residual strain calculations using $z_{\text {repeat, which is }}$ calculated to be the maximum of two values; one of which is the positive difference between the minimum and maximum values of the six calibration measurements taken before the data session and the other is the positive difference between the minimum and maximum values of the six measurements taken after the data session. As with $\sigma_{\text {zcal }}, z_{\text {repeat }}$ is assumed to scale linearly with height. The input values to the residual strain calculations are then varied as specified in Table 5 [with $d=\left(z_{x x}-z_{l F}\right) z_{\text {repeat }} /\left(2^{*} \mu_{6}\right)$ where $\mu_{6}$ is the average of the six calibration measurements from which $z_{\text {repeat }}$ was found]. For the three different input combinations, $\varepsilon_{r \text {-low }}$ and $\varepsilon_{r \text {-high }}$ are identified. Then, $w_{1 / 2}$ is calculated using (22), followed by the determination of $u_{\text {repeat }}$, assuming a uniform distribution, using the following equation:

$$
u_{\text {repeat }}=w_{1 / 2} / 1.732 \text {. }
$$

The uncertainty equation for $u_{\text {drift }}$ is found from the residual strain calculations using $z_{\text {drift }}$, which is calculated as follows: the average of the six calibration measurements before the data session (calave before) is determined, and the average of the six calibration measurements after the data session (calave after) is determined. Then, $z_{\text {drift }}$ is calculated as the positive difference of these two values. As with $\sigma_{z c a l}, z_{\text {drift }}$ is assumed to scale linearly with height. The input values to the residual strain calculations are then varied as specified in Table 5 [with $d=\left(z_{x x}-z_{l F}\right) z_{d r i f t} /(2 * \mu)$ ]. For the three different input combinations, $\varepsilon_{r-\text { low }}$ and $\varepsilon_{r \text {-high }}$ are identified. Then, $w_{1 / 2}$ is calculated using (22), followed by the determination of $u_{d r i f t}$, assuming a uniform distribution, using the following equation:

$$
u_{\text {drift }}=w_{1 / 2} / 1.732 \text {. }
$$

The uncertainty equation for $u_{\text {linear }}$ is found from the residual strain calculations using $z_{\text {linear }}$, which is the difference in height between two points times $z_{\text {perc }} / 100$ where $z_{\text {perc }}$ is the percent quoted by the interferometer manufacturer for the maximum deviation from linearity of the data scan over the total scan range divided by $1 \%$, such that $z_{\text {perc }}$ (typically less than 3 ) is unitless. The input values to the residual strain calculations are then varied as specified in Table 5 with $d=z_{\text {linear }}$ where $z_{\text {linear }}$ is given by the following equation:

$$
z_{\text {linear }}=\left(z_{x x}-z_{1 F}\right) \frac{z_{\text {perc }}}{100}
$$

with $z_{x x}$ being the column heading in the table. For the three different input combinations, $\varepsilon_{r \text {-low }}$ and $\varepsilon_{r \text {-high }}$ are identified. Then, $w_{1 / 2}$ is calculated using (22), followed by the determination of $u_{\text {linear }}$, assuming a uniform distribution, using the following equation:

$$
u_{\text {linear }}=w_{1 / 2} / 1.732 \text {. }
$$

\subsection{Strain Gradient Uncertainty Calculations}

In this subsection, a combined standard uncertainty equation is presented for use with strain gradient measurements. Six sources of uncertainty are identified 
with all other sources of uncertainty considered negligible. This uncertainty equation is also expanded to include ten sources of uncertainty. Knowledge of the additional sources of uncertainty can be a tremendous benefit when taking and analyzing other interferometeric measurements (such as $80 \mu \mathrm{m}$ step heights).

Table 8. Determination of the Strain Gradient Uncertainty Components*

\begin{tabular}{|l|c|c|c|c|}
\hline $\begin{array}{l}\text { Uncertainty } \\
\text { Component }\end{array}$ & $\begin{array}{c}\text { Varied } \\
\text { From }\end{array}$ & $\begin{array}{c}\text { Varied } \\
\text { To }\end{array}$ & $\begin{array}{c}\text { How } \\
\text { Varied } \\
* *\end{array}$ & $\begin{array}{c}\text { G } \\
\text { or } \\
\mathbf{u} \\
* * *\end{array}$ \\
\hline 1. $\boldsymbol{u}_{\boldsymbol{W}}$ & $\begin{array}{c}\text { max } s_{g} \text { value } \\
\text { from Trace } \mathrm{b}, \\
\mathrm{c}, \text { and d }\end{array}$ & $\begin{array}{c}\text { min } s_{g} \text { value } \\
\text { from Trace } \mathrm{b}, \\
\mathrm{c}, \text { and d }\end{array}$ & - & $\mathrm{u}$ \\
\hline 2. $\boldsymbol{u}_{\text {zres }}$ & $+(1 / 2) z_{\text {res }}$ & $-(1 / 2) z_{\text {res }}$ & 9 & $\mathrm{u}$ \\
\hline 3. $\boldsymbol{u}_{\text {samp }}$ & $+3 \sigma_{\text {samp }}$ & $-3 \sigma_{\text {samp }}$ & 9 & $\mathrm{G}$ \\
\hline 4. $\boldsymbol{u}_{\text {zcal }}$ & $+d$ & $-d$ & 10 & $\mathrm{G}$ \\
\hline 5. $\boldsymbol{u}_{\text {xcal }}$ & with & with & - & $\mathrm{G}$ \\
\hline 6. $\boldsymbol{u}_{\text {xres }}$ & $+(1 / 2) x_{\text {res }}$ & $-(1 / 2) x_{\text {res }}$ & 11 & $\mathrm{u}$ \\
\hline 7. $\boldsymbol{u}_{\text {Rave }}$ & $+3 \sigma_{\text {Rave }}$ & $-3 \sigma_{\text {Rave }}$ & 9 & $\mathrm{G}$ \\
\hline 8. $\boldsymbol{u}_{\text {noise }}$ & $+3 \sigma_{\text {noise }}$ & $-3 \sigma_{\text {noise }}$ & 9 & $\mathrm{G}$ \\
\hline 9. $\boldsymbol{u}_{\text {cert }}$ & $+d$ & $-d$ & 10 & $\mathrm{G}$ \\
\hline 10. $\boldsymbol{u}_{\text {repeat }}$ & $+d$ & $-d$ & 10 & $\mathrm{u}$ \\
\hline 11. $\boldsymbol{u}_{\text {drift }}$ & $+d$ & $-d$ & 10 & $\mathrm{u}$ \\
\hline 12. $\boldsymbol{u}_{\text {linear }}$ & $+d$ & $-d$ & 10 & $\mathrm{u}$ \\
\hline
\end{tabular}

* In this table, $d=3\left(z_{x}-z_{l}\right) \sigma_{z c a l} /$ cert to determine $u_{z c a l}$ where $z_{x}$ is the appropriate column heading in Table $10, d=3\left(z_{x}-z_{1}\right) \sigma_{\text {cert }} /$ cert to determine $u_{\text {cert }}, d=\left(z_{x}-z_{1}\right) z_{\text {repeat }} /\left(2 * \mu_{6}\right)$ to determine $u_{\text {repeat }}, d=\left(z_{x}-z_{1}\right) z_{\text {drift }} /(2 * \mu)$ to determine $u_{\text {drift }}$, and $d=z_{\text {linear }}$ to determine $u_{\text {linear }}$.

** The entries in this column specify the table number where the input variations can be found, if applicable.

*** "G" indicates a Gaussian distribution and " $u$ " indicates a uniform distribution.

With a few variations, the combined standard uncertainty equations and the calculations for each uncertainty component are similar to those presented for residual strain measurements. Therefore, refer to the previous subsection for the general approach. More specifically, refer to Tables $8,9,10$, and 11 where mention is made of Tables 3, 4, 5, and 6, respectively. In addition, replace the words "residual strain" with the words "strain gradient," replace $\varepsilon_{r-l o w}$ with $s_{\text {g-low, }} \boldsymbol{\varepsilon}_{r \text {-high }}$ with $s_{\text {g-high }}, z_{x x}$ with $z_{x}$, and replace (21), (22), (31), and (37) with (39), (40), (41), and (42), respectively, given by the following equations:

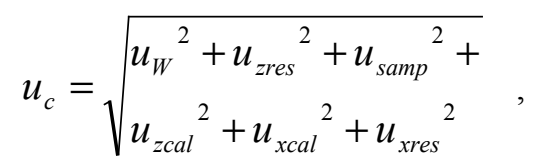

$$
\begin{gathered}
w_{l / 2}=\left(s_{\text {g-high }}-s_{\text {g-low }}\right) / 2, \\
u_{c}=\sqrt{\begin{array}{l}
u_{W}{ }^{2}+u_{\text {zres }}{ }^{2}+u_{\text {xcal }}{ }^{2}+u_{\text {xres }}{ }^{2}+ \\
u_{\text {Rave }}{ }^{2}+u_{\text {noise }}{ }^{2}+u_{\text {cert }}{ }^{2}+ \\
u_{\text {repeat }}{ }^{2}+u_{\text {drift }}{ }^{2}+u_{\text {linear }}{ }^{2}
\end{array}},
\end{gathered}
$$

and

$$
z_{\text {linear }}=\left(z_{x}-z_{1}\right) \frac{z_{\text {perc }}}{100}
$$

Note that (39) and (41) are the strain gradient combined standard uncertainty equations with six sources and ten sources of uncertainty, respectively. Data Analysis Sheet H [7] and ASTM Test Method E 2246-05 [10] use (39) and Data Analysis Sheet J uses (41) [7].

Table 9. Three Sets of Inputs for Strain Gradient Calculations to Determine $u_{z r e s}, u_{\text {samp }}, u_{\text {Rave }}$ and $u_{\text {noise }} *$

\begin{tabular}{|c|c|c|c|}
\hline & $\boldsymbol{z}_{\mathbf{1}}$ & $\boldsymbol{z}_{\mathbf{2}}$ & $\boldsymbol{z}_{3}$ \\
\hline $\mathbf{1}$ & $z_{1}$ & $z_{2}$ & $z_{3}$ \\
\hline $\mathbf{2}$ & $z_{1}+d$ & $z_{2}-d$ & $z_{3}+d$ \\
\hline $\mathbf{3}$ & $z_{1}-d$ & $z_{2}+d$ & $z_{3}-d$ \\
\hline
\end{tabular}

* In this table, $d=(1 / 2) z_{\text {res }}$ to determine $u_{\text {zress }}, d=3 \sigma_{\text {samp }}$ to determine $u_{\text {samp }}$, $d=3 \sigma_{\text {Rave }}$ to determine $u_{\text {Rave }}$, and $d=3 \sigma_{\text {noise }}$ to determine $u_{\text {noise }}$.

Table 10. Three Sets of Inputs for Strain Gradient Calculations to Determine $u_{z c a l}, u_{c e r t}, u_{\text {repeat }}$

\begin{tabular}{|c|c|c|c|}
\multicolumn{5}{|c|}{$u_{\text {drift, and } \text { linear }^{*}}$} \\
\hline $\mathbf{1}$ & $\boldsymbol{z}_{1}$ & $\boldsymbol{z}_{2}$ & $\boldsymbol{z}_{3}$ \\
\hline $\mathbf{2}$ & $\mathrm{z}_{1}$ & $z_{2}$ & $z_{3}$ \\
\hline $\mathbf{3}$ & $z_{1}$ & $\boldsymbol{z}_{2}+d$ & $\boldsymbol{z}_{3}+d$ \\
\hline
\end{tabular}

* In this table, $d=3\left(z_{x}-z_{l}\right) \sigma_{\text {zcal }} /$ cert where $z_{x}$ is the column heading to determine $u_{z c a l}, \quad d=3\left(z_{x}-z_{1}\right) \sigma_{\text {cert }} /$ cert to determine $u_{\text {cert }}$, $d=\left(z_{x}-z_{l}\right) z_{\text {repeat }} /\left(2 * \mu_{6}\right)$ to determine $u_{\text {repeat }}, d=\left(z_{x}-z_{l}\right) z_{\text {drift }} /(2 * \mu)$ to determine $u_{\text {drift }}$, and $d=z_{\text {linear }}$ to determine $u_{\text {linear }}$.

Table 11. Seven Sets of Inputs for Strain Gradient Calculations to Determine $u_{x r e s}$

\begin{tabular}{|c|c|c|c|}
\hline & $\boldsymbol{x}_{\mathbf{1}}$ & $\boldsymbol{x}_{\mathbf{2}}$ & $\boldsymbol{x}_{\mathbf{3}}$ \\
\hline $\mathbf{1}$ & $x_{1}$ & $x_{2}$ & $x_{3}$ \\
\hline $\mathbf{2}$ & $x_{1}+(1 / 2) x_{\text {res }}$ & $x_{2}$ & $x_{3}-(1 / 2) x_{\text {res }}$ \\
\hline $\mathbf{3}$ & $x_{1}-(1 / 2) x_{\text {res }}$ & $x_{2}$ & $x_{3}+(1 / 2) x_{\text {res }}$ \\
\hline $\mathbf{4}$ & $x_{1}+(1 / 2) x_{\text {res }}$ & $x_{2}+(1 / 2) x_{\text {res }}$ & $x_{3}-(1 / 2) x_{\text {res }}$ \\
\hline $\mathbf{5}$ & $x_{1}+(1 / 2) x_{\text {res }}$ & $x_{2}-(1 / 2) x_{\text {res }}$ & $x_{3}-(1 / 2) x_{\text {res }}$ \\
\hline $\mathbf{6}$ & $x_{1}-(1 / 2) x_{\text {res }}$ & $x_{2}+(1 / 2) x_{\text {res }}$ & $x_{3}+(1 / 2) x_{\text {res }}$ \\
\hline $\mathbf{7}$ & $x_{1}-(1 / 2) x_{\text {res }}$ & $x_{2}-(1 / 2) x_{\text {res }}$ & $x_{3}+(1 / 2) x_{\text {res }}$ \\
\hline
\end{tabular}




\section{Round Robin Results}

The reproducibility and repeatability results for inplane length are given in subsection 5.1, for residual strain in subsection 5.2, and for strain gradient in subsection 5.3.

The reproducibility measurements were performed using the same test methods at independent laboratories. At least six independent laboratories must submit "validated" measurement results before the results can be recorded in the precision and bias statement of an ASTM standard test method.

The repeatability measurements were performed using the same test method, in the same laboratory (NIST), by the same operator, with the same equipment, in the shortest practicable period of time. These measurements were done on random test structures.

In each subsection one or two tables will be presented, either one for the reproducibility results and one for the repeatability results, or one for both the reproducibility and repeatability results, with the precision data appearing in bold print. In each table, the number of collected measurements $(n)$ is specified. The tables also include the average (i.e., $L_{\text {ave }}, \varepsilon_{\text {rave }}$, or $s_{\text {gave }}$ ) of the reproducibility (and/or repeatability) measurement results and the 95\% limits (as given by 2.8 times the standard deviation [11] in the form of a percent). Below this, the average of the reproducibility (and/or repeatability) combined standard uncertainty [4] values $\left(u_{\text {cave }}\right)$ and the $95 \%$ limits for $u_{c}$ are presented.

In the tables for in-plane length measurements, the magnifications ( $\mathrm{mag}$ ) are also included along with the values for $\Delta L$ (where $\Delta L=L_{\text {ave }}-L_{d e s}$ ).

\subsection{In-Plane Length Results}

This subsection includes in-plane length measurements with transitional edges facing each other (such as Edges "1" and "2," as shown in Figures 2 and 3) and measurements with transitional edges facing the same direction (such as Edges " 1 " and "5," as shown in Figures 2 and 3). Tables 12 and 13 present the reproducibility and repeatability results, respectively, for the in-plane length measurements with transitional edges facing each other, and Tables 14 and 15 present similar results for in-plane length measurements with transitional edges facing the same direction.

In particular, note in Tables 12 and 14 the magnifications used for the specified values of the design length $\left(L_{d e s}\right)$. Not all laboratories had the same magnifications available; therefore, each laboratory was instructed to use the highest magnification available for the given measurement. The underlined value was the magnification used for the repeatability measurements.

Table 12 includes the in-plane length results from the $650 \mu \mathrm{m}$ long fixed-fixed beams from the residual strain measurements. Similar $650 \mu \mathrm{m}$ long measurements are not included in Table 13 since repeatability measurements at a magnification of $5 \times$ are already available with the $1000 \mu \mathrm{m}$ long measurements.
Table 12. Reproducibility of Round Robin Measurement Results for In-Plane Length Measurements When the Transitional Edges Face Each Other

\begin{tabular}{|c|c|c|c|c|c|c|}
\hline & $\begin{array}{c}L_{d e s} \\
25 \\
\mu \mathrm{m} \\
\end{array}$ & $\begin{array}{c}L_{d e s} \\
\mathbf{8 0} \\
\mu \mathrm{m} \\
\end{array}$ & $\begin{array}{l}L_{d e s} \\
200 \\
\mu \mathrm{m} \\
\end{array}$ & $\begin{array}{l}L_{d e s} \\
500 \\
\mu \mathrm{m} \\
\end{array}$ & $\begin{array}{l}L_{d e s} \\
650 \\
\mu \mathrm{m} \\
\end{array}$ & $\begin{array}{c}L_{d e s} \\
1000 \\
\mu \mathrm{m} \\
\end{array}$ \\
\hline$n$ & 7 & 7 & 6 & $6^{A}$ & 7 & $6^{A}$ \\
\hline $\begin{array}{l}\text { mag } \\
(\times)\end{array}$ & $\begin{array}{c}100, \frac{80}{39}, \\
50,39 \\
20,10, \\
u^{D}\end{array}$ & $\begin{array}{c}50, \frac{40}{25}, \\
25,2, \\
10,10, u\end{array}$ & $\begin{array}{c}25,20.4 \\
\frac{20}{10}, 10 \\
10\end{array}$ & $\begin{array}{c}10.2, \underline{10} \\
10,10, \\
5,5\end{array}$ & $\begin{array}{c}25,7.8 \\
\underline{5}, 5,5 \\
5, u\end{array}$ & $\begin{array}{l}\underline{5}, 5,5, \\
5,5,5\end{array}$ \\
\hline $\begin{array}{l}L_{\text {ave }} \\
(\mu \mathrm{m})\end{array}$ & 24.91 & 79.70 & 200.61 & 497.8 & 651.4 & 999.8 \\
\hline $\begin{array}{l}95 \% \\
\text { limits } \\
\text { for } L \\
\end{array}$ & $\pm 23.9 \%$ & $\pm 9.3 \%$ & $\pm 2.8 \%$ & $\pm 1.1 \%$ & $\pm 1.1 \%$ & $\pm 0.7 \%$ \\
\hline $\begin{array}{l}u_{\text {cave }} \\
(\mu \mathrm{m})^{B}\end{array}$ & $\begin{array}{c}0.60 \\
(2.4 \%)\end{array}$ & $\begin{array}{c}0.71 \\
(0.9 \%)\end{array}$ & $\begin{array}{c}0.86 \\
(0.4 \%)\end{array}$ & $\begin{array}{c}1.5 \\
(0.3 \%)\end{array}$ & $\begin{array}{c}1.6 \\
(0.2 \%)\end{array}$ & $\begin{array}{c}2.5 \\
(0.3 \%)\end{array}$ \\
\hline $\begin{array}{l}95 \% \\
\text { limits } \\
\text { for } u_{c}{ }^{\text {B }}\end{array}$ & $\pm 257 \%$ & $\pm 172 \%$ & $\pm 166 \%$ & $\pm 170 \%$ & $\pm 203 \%$ & $\pm 63 \%$ \\
\hline $\begin{array}{l}\Delta L \\
(\mu \mathrm{m})\end{array}$ & -0.09 & -0.30 & 0.61 & -2.2 & 1.4 & -0.2 \\
\hline
\end{tabular}

${ }^{A}$ Three of these measurements were taken from the same instrument by two different operators.

${ }^{B}$ As determined in Test Method E 2244-02 [1] using (9) with $u_{x c a l}=u_{x r e s}=0$. ${ }^{C}$ Underlined values correspond to the magnifications used for the repeatability measurements.

$D$ The symbol " $u$ " stands for "unknown." The magnification was not reported by the round robin participant.

Table 13. Repeatability of NIST Measurement Results for In-Plane Length Measurements When the Transitional Edges Face Each Other

\begin{tabular}{|c|c|c|c|c|c|}
\hline & $\begin{array}{c}L_{d e s} \\
25 \\
\mu \mathrm{m}\end{array}$ & $\begin{array}{c}L_{d e s} \\
\mathbf{8 0} \\
\mu \mathrm{m}\end{array}$ & $\begin{array}{l}L_{\text {des }} \\
200 \\
\mu \mathrm{m}\end{array}$ & $\begin{array}{l}L_{\text {des }} \\
\mathbf{5 0 0} \\
\mu \mathrm{m}\end{array}$ & $\begin{array}{c}L_{d e s} \\
1000 \\
\mu \mathrm{m}\end{array}$ \\
\hline$n$ & 48 & 48 & 48 & 48 & 48 \\
\hline $\begin{array}{l}\text { mag } \\
(\times)\end{array}$ & 80 & 40 & 20 & 10 & 5 \\
\hline $\begin{array}{l}L_{\text {ave }} \\
(\mu \mathrm{m})\end{array}$ & 24.37 & 79.76 & 199.10 & 495.0 & 995.5 \\
\hline $\begin{array}{l}95 \% \\
\text { limits } \\
\text { for } L\end{array}$ & $\pm 1.1 \%$ & $\pm 0.3 \%$ & $\pm 0.2 \%$ & $\pm 0.5 \%$ & $\pm 0.7 \%$ \\
\hline $\begin{array}{l}u_{\text {cave }} \\
(\mu \mathrm{m})^{A}\end{array}$ & $\begin{array}{c}0.33 \\
(1.34 \%)\end{array}$ & $\begin{array}{c}1.11 \\
(1.4 \%)\end{array}$ & $\begin{array}{c}1.08 \\
(0.5 \%)\end{array}$ & $\begin{array}{c}1.9 \\
(0.4 \%)\end{array}$ & $\begin{array}{c}3.6 \\
(0.4 \%)\end{array}$ \\
\hline $\begin{array}{l}95 \% \\
\operatorname{limits} \\
\text { for } u_{c}{ }^{A}\end{array}$ & $\pm 14 \%$ & $\pm 6 \%$ & $\pm 10 \%$ & $\pm 35 \%$ & $\pm 57 \%$ \\
\hline $\begin{array}{l}u_{\text {cave }} \\
(\mu \mathrm{m})^{B}\end{array}$ & $\begin{array}{c}0.23 \\
(0.95 \%)\end{array}$ & $\begin{array}{c}1.05 \\
(1.3 \%)\end{array}$ & $\begin{array}{c}0.95 \\
(0.5 \%)\end{array}$ & $\begin{array}{c}1.7 \\
(0.3 \%)\end{array}$ & $\begin{array}{c}3.2 \\
(0.3 \%)\end{array}$ \\
\hline $\begin{array}{l}95 \% \\
\text { limits } \\
\text { for } u_{c}{ }^{B}\end{array}$ & $\pm 29 \%$ & $\pm 7 \%$ & $\pm 13 \%$ & $\pm 46 \%$ & $\pm 72 \%$ \\
\hline $\begin{array}{l}\Delta L \\
(\mu \mathrm{m})\end{array}$ & -0.63 & -0.24 & -0.90 & -5.0 & -4.5 \\
\hline
\end{tabular}

${ }^{A}$ As determined in ASTM Test Method E 2244-05 [8] using (9).

${ }^{B}$ As determined in ASTM Test Method E 2244-02 [1] using (9) with $u_{\text {xcal }}=u_{\text {xres }}=0$. 
Table 14. Reproducibility of Round Robin Measurement Results for In-Plane Length Measurements When the

Transitional Edges Face the Same Direction

\begin{tabular}{|c|c|c|c|c|c|}
\hline & $\begin{array}{c}L_{d e s} \\
\mathbf{6 0} \\
\mu \mathrm{m}\end{array}$ & $\begin{array}{l}L_{d e s} \\
\mathbf{1 1 5} \\
\mu \mathrm{m}\end{array}$ & $\begin{array}{l}L_{d e s} \\
235 \\
\mu \mathbf{m}\end{array}$ & $\begin{array}{l}L_{\text {des }} \\
\mathbf{5 3 5} \\
\mu \mathrm{m}\end{array}$ & $\begin{array}{c}L_{d e s} \\
1035 \\
\mu \mathbf{m}\end{array}$ \\
\hline$n$ & $6^{A}$ & 6 & $6^{A}$ & $6^{B}$ & $6^{B}$ \\
\hline $\operatorname{mag}(\times)$ & $\begin{array}{l}\frac{80,80}{50,39} \\
20,10\end{array}$ & $\begin{array}{l}\frac{40,25}{25}, 25 \\
10,10\end{array}$ & $\begin{array}{c}20.4, \underline{20} \\
20,10 \\
10,5\end{array}$ & $\begin{array}{c}10.2, \underline{10} \\
10,10 \\
5,5\end{array}$ & $\begin{array}{c}5.9,5,5, \\
5,5,5\end{array}$ \\
\hline$L_{\text {ave }}(\mu \mathrm{m})$ & 59.68 & 115.34 & 235.79 & 533.8 & 1035.1 \\
\hline $\begin{array}{l}95 \% \\
\operatorname{limits} \\
\text { for } L\end{array}$ & $\pm 2.9 \%$ & $\pm 6.1 \%$ & $\pm 2.4 \%$ & $\pm 1.5 \%$ & $\pm 0.7 \%$ \\
\hline $\begin{array}{l}u_{\text {cave }} \\
(\mu \mathrm{m})^{C}\end{array}$ & $\begin{array}{c}0.22 \\
(0.4 \%)\end{array}$ & $\begin{array}{c}0.32 \\
(0.3 \%)\end{array}$ & $\begin{array}{c}0.43 \\
(0.2 \%)\end{array}$ & $\begin{array}{c}0.7 \\
(0.1 \%)\end{array}$ & $\begin{array}{c}1.1 \\
(0.1 \%)\end{array}$ \\
\hline $\begin{array}{l}95 \% \\
\text { limits } \\
\text { for } u_{c}{ }^{C}\end{array}$ & $\pm 331 \%$ & $\pm 193 \%$ & $\pm 217 \%$ & $\pm 93 \%$ & $\pm 16 \%$ \\
\hline$\Delta L(\mu \mathrm{m})$ & -0.32 & 0.34 & 0.79 & -1.2 & 0.1 \\
\hline
\end{tabular}

${ }^{A}$ Two of these measurements were taken from the same instrument by different operators.

${ }^{B}$ Three of these measurements were taken from the same instrument by two different operators.

$C$ As determined in Test Method E 2244-02 [1] using (9) with $u_{x c a l}=u_{x r e s}=0$.

Table 15. Repeatability of NIST Measurement Results for In-Plane Length Measurements When the Transitional Edges Face the Same Direction

\begin{tabular}{|c|c|c|c|c|c|}
\hline & $\begin{array}{c}L_{d e s} \\
60 \\
\mu \mathrm{m}\end{array}$ & $\begin{array}{l}L_{d e s} \\
115 \\
\mu \mathrm{m}\end{array}$ & $\begin{array}{l}L_{d e s} \\
235 \\
\mu \mathrm{m}\end{array}$ & $\begin{array}{l}L_{d e s} \\
535 \\
\mu \mathrm{m}\end{array}$ & $\begin{array}{c}L_{d e s} \\
1035 \\
\mu \mathrm{m}\end{array}$ \\
\hline$n$ & 48 & 48 & 48 & 48 & 48 \\
\hline $\begin{array}{l}\text { mag } \\
(\times)\end{array}$ & 80 & 40 & 20 & 10 & 5 \\
\hline $\begin{array}{l}L_{\text {ave }} \\
(\mu \mathrm{m})\end{array}$ & 59.56 & 115.96 & 234.67 & 532.2 & 1035.0 \\
\hline $\begin{array}{l}95 \% \\
\text { limits } \\
\text { for } L\end{array}$ & $\pm 0.6 \%$ & $\pm 0.5 \%$ & $\pm 0.3 \%$ & $\pm 0.1 \%$ & $\pm 0.2 \%$ \\
\hline $\begin{array}{l}u_{\text {cave }} \\
(\mu \mathrm{m})^{A}\end{array}$ & $\begin{array}{c}0.54 \\
(0.9 \%)\end{array}$ & $\begin{array}{c}0.55 \\
(0.5 \%)\end{array}$ & $\begin{array}{c}0.64 \\
(0.3 \%)\end{array}$ & $\begin{array}{c}1.1 \\
(0.2 \%)\end{array}$ & $\begin{array}{c}2.0 \\
(0.2 \%)\end{array}$ \\
\hline $\begin{array}{l}95 \% \\
\text { limits } \\
\text { for } u_{c}{ }^{A}\end{array}$ & $\pm 0.6 \%$ & $\pm 0.4 \%$ & $\pm 0.2 \%$ & $\pm 0.1 \%$ & $\pm 0.1 \%$ \\
\hline $\begin{array}{l}u_{\text {cave }} \\
(\mu \mathrm{m})^{B}\end{array}$ & $\begin{array}{c}0.07 \\
(0.1 \%)\end{array}$ & $\begin{array}{c}0.14 \\
(0.1 \%)\end{array}$ & $\begin{array}{c}0.26 \\
(0.1 \%)\end{array}$ & $\begin{array}{c}0.5 \\
(0.1 \%)\end{array}$ & $\begin{array}{c}1.1 \\
(0.1 \%)\end{array}$ \\
\hline $\begin{array}{l}95 \% \\
\text { limits } \\
\text { for } u_{c}{ }^{B}\end{array}$ & $\pm 0 \%$ & $\pm 0 \%$ & $\pm 0 \%$ & $\pm 0 \%$ & $\pm 0 \%$ \\
\hline $\begin{array}{l}\Delta L \\
(\mu \mathrm{m})\end{array}$ & -0.44 & 0.96 & -0.33 & -2.8 & 0.0 \\
\hline
\end{tabular}

${ }^{A}$ As determined in ASTM Test Method E 2244-05 [8] using (9).

${ }^{B}$ As determined in ASTM Test Method E 2244-02 [1] using (9) with $u_{x c a l}=u_{x r e s}=0$.

The test method for in-plane length measurements emphasizes two values, the in-plane length measurement, $L$, and the combined standard uncertainty [4], $u_{c}$, of that measurement. The true length is believed to lie in the interval $L+/-3 u_{c}$ with a level of confidence of approximately $99.7 \%$ assuming a Gaussian distribution [6].

Figure 9 illustrates reproducibility and repeatability bias data for $L$. This figure consists of four plots of $\Delta L$ versus $L_{d e s}$ where $\Delta L=L_{\text {ave }}-L_{\text {des }}$. These plots are for the reproducibility and repeatability measurements in Data Sheets $\mathrm{A}$ and $\mathrm{B}$. The average $\Delta L$ value $\left(\Delta L_{\text {ave }}\right)$ for each plot is given. For the reproducibility and repeatability data from Data Sheet B and the reproducibility data from Data Sheet A, assuming the design lengths $\left(L_{d e s}\right)$ are the true length values, due to the very small values of $\Delta L_{\text {ave }}$ in combination with at least two values of $\Delta L$ being greater than or equal to zero and at least two being less than or equal to zero for each curve (as given in Tables 12, 14, and $15)$, it can be concluded that there is no obvious bias to this data.

The repeatability data from Data Sheet A show the highest $\left|\Delta L_{\text {ave }}\right|$ value with all the measurements of $L_{\text {ave }}$ being less than $L_{d e s}$ (as given in Table 13). Therefore, there may be a bias towards measuring lower values of $L$ when using Data Sheet A at this laboratory, and the degree of the resulting bias varies with magnification. Even though these data were calibrated, it should be emphasized that calibration of the interferometer is considered mandatory for in-plane length measurements. The interferometer is calibrated in-plane using a $10 \mu \mathrm{m}$ grid or finer grid ruler. If the calibration is not done at each magnification, a bias to the measurements is expected. The direction and degree of the resulting bias are different for each magnification of each interferometer. Then, $c a l_{x}$ is calculated using (16) and all $x$-values are multiplied by $c a l_{x}$ to obtain calibrated $x$ data values.

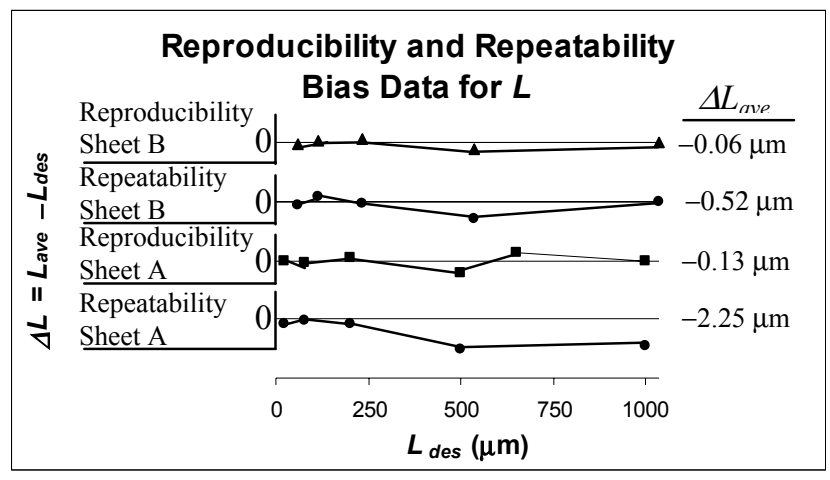

Figure 9. Reproducibility and repeatability bias data for $L$.

Now, consider the trends associated with the average combined standard uncertainty value $\left(u_{\text {cave }}\right)$ as given in Figures 10 and 11 for Data Sheets A and B, respectively. ${ }^{6}$ In both of these figures, $u_{\text {cave }}$ increases with increasing length primarily due to the increase in the pixel-to-pixel spacings associated with the lower-powered objectives that are used for the longer length measurements. Also, these

\footnotetext{
${ }^{6}$ In this discussion, the equation for $u_{c}$ in (9) does not include $u_{x c a l}$ and $u_{\text {xres. }}$.
} 
figures show that the reproducibility and repeatability measurements are somewhat comparable. For Data Sheet A, $u_{c}=\left(L_{\max }-L_{\min }\right) / 6$, and if the data points determining $L_{\max }$ and $L_{\min }$ are chosen in the manner specified in the standard test method, this result is expected. For Data Sheet $\mathrm{B}$, the equation for $u_{c}$ can be rewritten [6] to be $u_{c}=$ 2 sep/3 where sep is the pixel-to-pixel separation for the given magnification. Therefore, $u_{c}$ can be determined before the measurement is even taken. Therefore, the reproducibility and repeatability measurements should be comparable.

Probing deeper into this, Figure 11 (in combination with the magnifications specified in Table 14) indicates that the interferometer used at NIST for the repeatability measurements has comparable values for sep for the $L_{\text {des }}=1035 \mu \mathrm{m}$ measurement taken at $5 \times$ in comparison to the interferometers used by the other laboratories that participated in this round robin. However, this laboratory benefited by having 5 different magnifications with which to take measurements. Therefore, for the smaller values of $L_{d e s}$, due to a relatively higher-powered objective that was used for the measurements in comparison to the other laboratories, this laboratory was able to achieve lower values for $u_{\text {cave }}$. This could imply that the effective technical lifetime of an interferometer can be extended by purchasing multiple objectives.

Comparing $u_{\text {cave }}$ in Figures 10 and 11, the values for $u_{\text {cave }}$ from Data Sheet B are considerably less than those from Data Sheet A. This implies that more precise in-plane length measurements are possible when the transitional edges face the same direction.

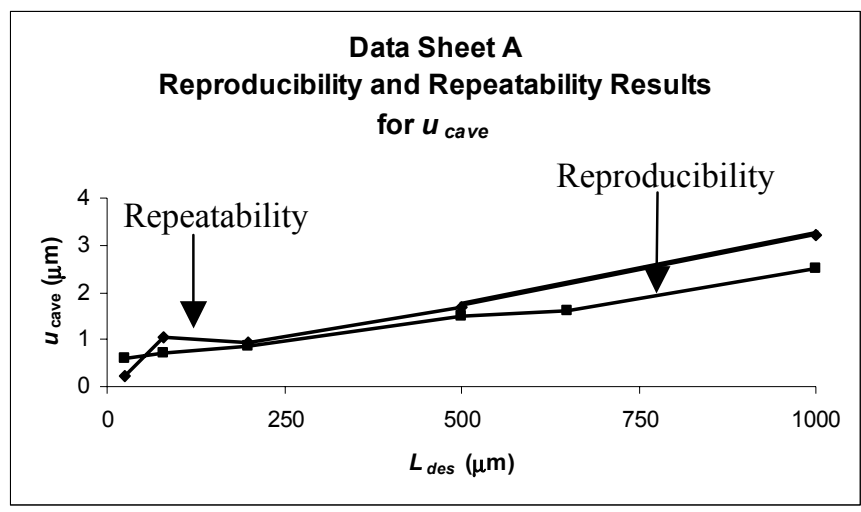

Figure 10. Comparing reproducibility and repeatability results for $u_{\text {cave }}$ in Data Sheet $A$.

Comments concerning the round robin data include the following:

a) Precision: The precision data for $L$ and the precision data for the combined standard uncertainty, $u_{c}$, of that measurement, appear in bold print in Tables 12 through 15 . The $95 \%$ limits for $L$ given in these tables indicate that the reproducibility results (e.g., $\pm 2.8 \%$ for Data Sheet A in Table 12 for $\left.L_{d e s}=200 \mu \mathrm{m}\right)$ are much poorer than the corresponding repeatability results (i.e., $\pm 0.2 \%$ in Table 13). This can be due to different magnifications used for the measurements (especially for smaller values of $L_{d e s}$ ), the calibrations of the instruments being slightly different, the use of different instruments, and a different person taking the measurements and analyzing the data.

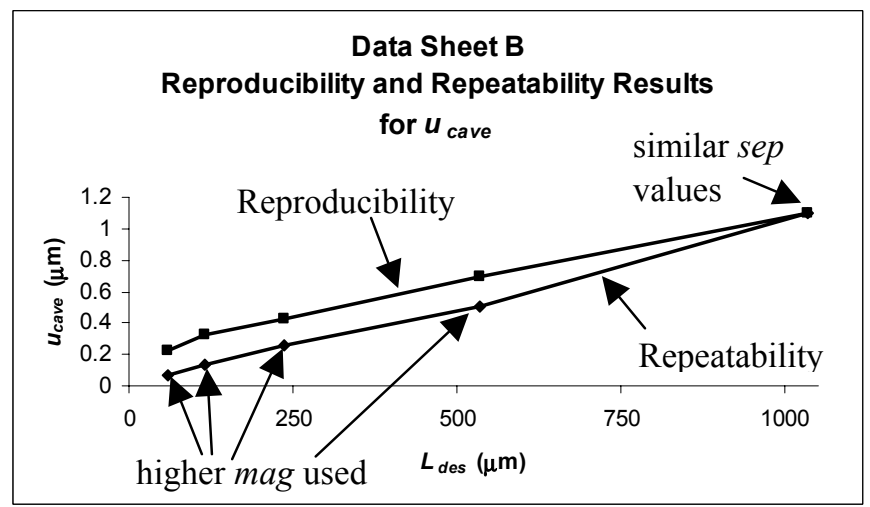

Figure 11. Comparing reproducibility and repeatability results for $u_{\text {cave }}$ in Data Sheet $B$.

b) Bias: As mentioned previously, the data in Figure 9 suggests no bias associated with the length data, but a tendency for repeatability Data Sheet A length data to be less than $L_{d e s}$ for this laboratory for all magnifications. The degree of the resulting bias is different for each magnification.

\subsection{Residual Strain Results}

Table 16 presents the residual strain reproducibility and repeatability results. For the reproducibility measurements, the fixed-fixed beams measured had either a 0 degree or a 90 degree orientation and lengths ranging from $550 \mu \mathrm{m}$ to $700 \mu \mathrm{m}$. For the repeatability measurements, the fixedfixed beams measured had different orientations and lengths ranging from $600 \mu \mathrm{m}$ to $750 \mu \mathrm{m}$. All fixed-fixed beams were $10 \mu \mathrm{m}$ wide.

Comments concerning the round robin data include the following:

a) Plots: In this round robin, random length fixedfixed beams were measured. As such, there were at least two variables (orientation and length) as discussed below:

i) Orientation: Figure 12 is a plot of $-\mathcal{E}_{r}$ versus orientation. In this plot, there is no obvious orientation dependence considering the values for $\varepsilon_{\text {rave }}$ are approximately the same for the two different orientations. However, the $95 \%$ limits for the data taken from the test structures with a 0 degree orientation are approximately half the $95 \%$ limits for the data taken from the test structures with a 90 degree orientation.

ii) Length: Figure 13 is a plot of $-\varepsilon_{r}$ versus length. In this plot, the data indicate there is no obvious length dependence.

b) Precision: The reproducibility and repeatability precision data appear in Table 16 in bold print. Note that for the $95 \%$ limits for $\varepsilon_{r}$, the repeatability data (i.e., $\pm 15.9 \%$ ) are less than the reproducibility data (i.e., $\pm 27.8 \%$ ). This is due to the repeatability measurements 
being taken at the same laboratory using the same instrument by the same operator.

Table 16. Residual Strain Measurement Results

\begin{tabular}{|c|c|c|}
\hline & $\begin{array}{c}\text { Reproducibility } \\
\text { results } \\
L_{d e s}=550-700 \mu \mathrm{m}\end{array}$ & $\begin{array}{c}\text { Repeatability } \\
\text { results } \\
L_{d e s}=600-750 \mu \mathrm{m}\end{array}$ \\
\hline$n$ & $6^{A}$ & 24 \\
\hline $\mathcal{E}_{\text {rave }}$ & $-44.02 \times 10^{-6}$ & $-41.65 \times 10^{-6}$ \\
\hline $\begin{array}{l}95 \% \text { limits } \\
\text { for } \varepsilon_{\mathrm{r}}\end{array}$ & $\pm 27.8 \%$ & $\pm 15.9 \%$ \\
\hline$u_{\text {cave }}^{B}$ & - & $0.53 \times 10^{-6}(1.3 \%)$ \\
\hline $\begin{array}{l}95 \% \text { limits } \\
\text { for } u_{c}{ }^{B}\end{array}$ & - & $\pm 79.1 \%$ \\
\hline$u_{\text {cave }}{ }^{C}$ & - & $0.57 \times 10^{-6}(1.4 \%)$ \\
\hline $\begin{array}{l}95 \% \text { limits } \\
\text { for } u_{c}{ }^{C}\end{array}$ & - & $\pm 55.8 \%$ \\
\hline$u_{\text {cave }}{ }^{D}$ & $1.07 \times 10^{-6}(2.4 \%)$ & $0.77 \times 10^{-6}(1.8 \%)$ \\
\hline $\begin{array}{l}95 \% \text { limits } \\
\text { for } u_{c}{ }^{D}\end{array}$ & $\pm 132 \%$ & $\pm 136 \%$ \\
\hline
\end{tabular}

${ }^{A}$ Two of these measurements were taken from the same instrument by different operators.

${ }^{B}$ As determined in ASTM Test Method E 2245-05 [9] using (21).

${ }^{C}$ As determined using (31).

${ }^{D}$ As determined in ASTM Test Method E 2245-02 [2], the $u_{\text {samp }}$ and $u_{\text {zcal }}$ components in the $u_{c}$ calculation were combined into one component. As such, for this component, the $99 \%$ limits, assuming a uniform (that is, rectangular) probability distribution, were represented by a $+/-20 \mathrm{~nm}$ variation in the $z$-value of the data points. Also in Test Method E $2245-02, u_{\text {zres }}=u_{\text {xcal }}=u_{\text {xres }}=u_{\text {xresL }}=0$.

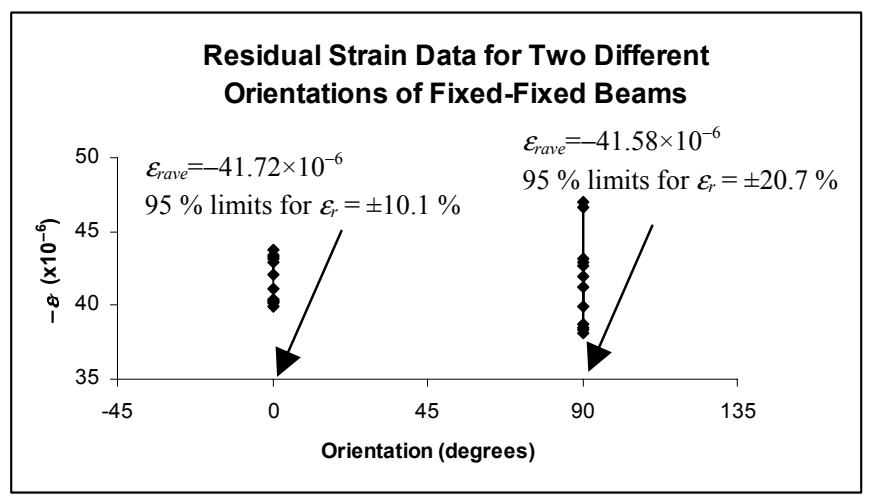

Figure 12. A plot of $-\mathcal{E}_{r}$ versus orientation.

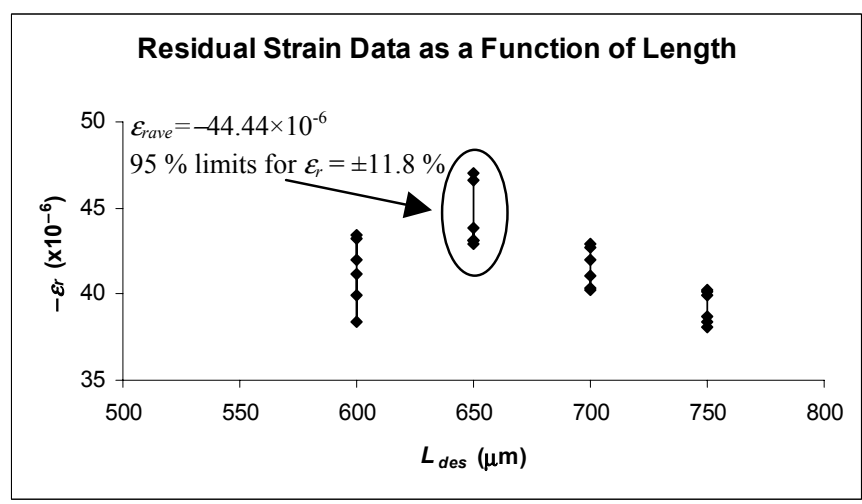

Figure 13. A plot of $-\mathcal{E}_{r}$ versus length. c) Bias: No information can be presented on the bias of the procedure in Test Method E 2245 for measuring residual strain because no material having an accepted reference value is available.

\subsection{Strain Gradient Results}

Table 17 presents the strain gradient reproducibility and repeatability results. For the reproducibility measurements, the cantilevers measured had either a 0 degree or a 90 degree orientation and lengths ranging from $500 \mu \mathrm{m}$ to 650 $\mu \mathrm{m}$. For the repeatability measurements, the cantilevers measured had different orientations and lengths from $400 \mu \mathrm{m}$ to $750 \mu \mathrm{m}$. All cantilevers were $10 \mu \mathrm{m}$ wide.

\section{Table 17. Strain Gradient Measurement Results}

\begin{tabular}{|c|c|c|c|}
\hline & $\begin{array}{c}\text { Reproducibilit } \\
\text { y results } \\
L_{d e s}= \\
500-650 \mu \mathrm{m}\end{array}$ & $\begin{array}{c}\text { Repeatability } \\
\text { results } \\
L_{d e s}= \\
500-650 \mu \mathrm{m}\end{array}$ & $\begin{array}{c}\text { Repeatability } \\
\text { results } \\
L_{d e s}= \\
400-750 \mu \mathrm{m} \\
\end{array}$ \\
\hline$n$ & 6 & 24 & 48 \\
\hline$S_{\text {gave }}$ & $4.67 \mathrm{~m}^{-1}$ & $4.71 \mathrm{~m}^{-1}$ & $4.97 \mathrm{~m}^{-1}$ \\
\hline $\begin{array}{l}95 \% \\
\text { limits } \\
\text { for } s_{g} \\
\end{array}$ & $\pm 51.6 \%$ & $\pm 35.5 \%$ & $\pm 56.1 \%$ \\
\hline$u_{\text {cave }}{ }^{A}$ & - & $\begin{array}{l}0.47 \mathrm{~m}^{-1} \\
(10.1 \%)\end{array}$ & $\begin{array}{l}0.56 \mathrm{~m}^{-1} \\
(11.2 \%)\end{array}$ \\
\hline $\begin{array}{l}95 \% \\
\text { limits } \\
\text { for } u_{c}{ }^{A}\end{array}$ & - & $\pm 142 \%$ & $\pm 176 \%$ \\
\hline$u_{\text {cave }}^{B}$ & - & $\begin{array}{c}0.44 \mathrm{~m}^{-1} \\
(9.5 \%)\end{array}$ & $\begin{array}{l}0.52 \mathrm{~m}^{-1} \\
(10.5 \%)\end{array}$ \\
\hline $\begin{array}{l}95 \% \\
\text { limits } \\
\text { for } u_{c}{ }^{B}\end{array}$ & - & $\pm 151 \%$ & $\pm 182 \%$ \\
\hline$u_{\text {cave }}{ }^{C}$ & $\begin{array}{l}0.56 \mathrm{~m}^{-1} \\
(12.0 \%)\end{array}$ & $\begin{array}{l}0.73 \mathrm{~m}^{-1} \\
(15.5 \%)\end{array}$ & $\begin{array}{l}0.84 \mathrm{~m}^{-1} \\
(16.9 \%)\end{array}$ \\
\hline $\begin{array}{l}95 \% \\
\text { limits } \\
\text { for } u_{c}{ }^{C}\end{array}$ & $\pm 147 \%$ & $\pm 95.3 \%$ & $\pm 150 \%$ \\
\hline \multicolumn{4}{|c|}{$\begin{array}{l}{ }^{A} \text { As determined in ASTM Test Method E 2246-05 [10] using (39). } \\
{ }^{B} \text { As determined using (41). } \\
{ }^{C} \text { As determined in ASTM Test Method E 2246-02 [3], the } u_{\text {samp }} \text { and } u_{z c a l} \\
\text { components in the } u_{c} \text { calculation were combined into one component. For } \\
\text { this component, assuming a uniform (that is, rectangular) probability } \\
\text { distribution, the } 99 \% \text { limits were represented by a }+/-20 \mathrm{~nm} \text { variation in } \\
\text { the } z \text {-value of the data points. Also, in Test Method E 2246-02, } \\
u_{z \text { zes }}=u_{\text {xcal }}=u_{\text {xres }}=0 \text {. }\end{array}$} \\
\hline
\end{tabular}

Comments concerning the round robin data include the following:

a) Plots: In this round robin, random length cantilevers were measured. As such, there were at least two variables (orientation and length) as discussed below.

i) Orientation: Figure 14 is a plot of $s_{g}$ versus orientation. In this plot, there is no obvious orientation dependence.

ii) Length: Figure 15 is a plot of $s_{g}$ versus design length. In this plot, the data indicate a decrease in the strain gradient for increasing length (for $L_{d e s}=400 \mu \mathrm{m}$ to $600 \mu \mathrm{m}$ ) that levels off (from $L_{d e s}=600 \mu \mathrm{m}$ to $750 \mu \mathrm{m}$ ). 


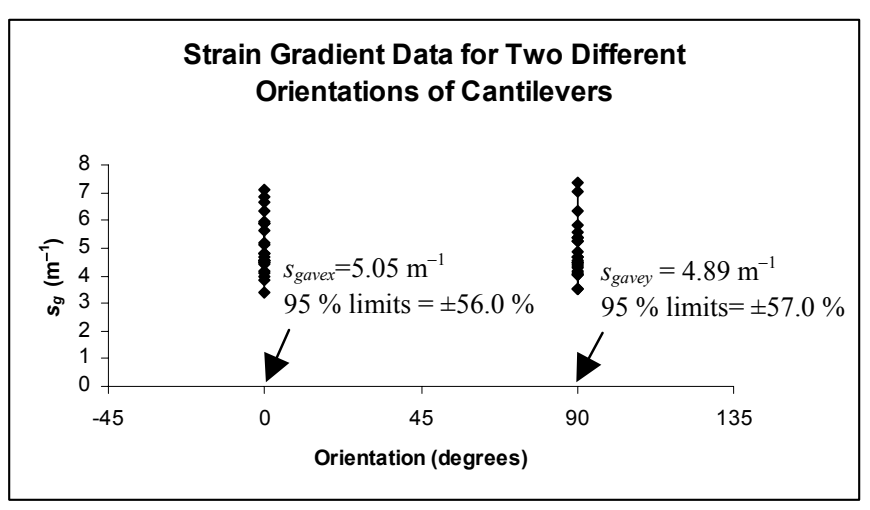

Figure 14. A plot of $s_{g}$ versus orientation.

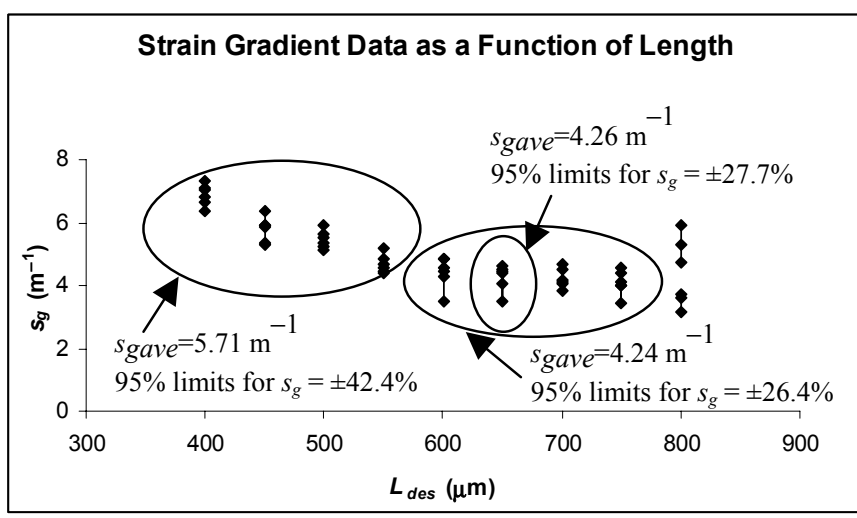

Figure 15. A plot of $s_{g}$ versus length for two different orientations.

b) Precision: The reproducibility and repeatability precision data appear in Table 17 in bold print. Note that for the $95 \%$ limits for $s_{g}$, the repeatability data (i.e., $\pm 35.5 \%$ ) is less than the reproducibility data (i.e., $\pm 51.6 \%$ ) for the same span of design lengths. This is due to the repeatability measurements being taken at the same laboratory using the same instrument by the same operator. It is interesting to note that the $u_{\text {cave }}$ values for the repeatability measurements are slightly higher than the $u_{\text {cave }}$ values for the reproducibility measurements.

c) Bias: No information can be presented on the bias of the procedure in Test Method E 2246 for measuring strain gradient because no material having an accepted reference value is available.

\section{Conclusions}

ASTM standard test method precision and bias data obtained from the MEMS Length and Strain Round Robin were presented for in-plane length, residual strain, and strain gradient measurements. The final results are incorporated in the ASTM standard test methods [8-10].

In addition to the precision and bias data presented in Tables 12 through 17, this paper presented the combined standard uncertainty equations [namely, (9), (21), and (39) for in-plane length, residual strain, and strain gradient measurements, respectively] used in the validated ASTM standard test methods [8-10]. The determination of each uncertainty component was discussed in detail.

The combined standard uncerainty equations for residual strain and strain gradient were further expanded into (31) and (41), respectively, and each additional uncertainty component discussed in detail. Knowledge of the additional sources of uncertainty can be a tremendous benefit when taking and analyzing other interferometric measurements (such as, $80 \mu \mathrm{m}$ step heights).

One positive result of this round robin analysis is the reduction of interlaboratory differences in the parametric measurements due in part to the verification sections in the data analysis sheets. Some round robin results for reproducibility were not incorporated in the summary results because of lack of compliance with these quality control checks.

And lastly, the following guidelines should be of value to the MEMS industry, when communicating data obtained using these ASTM standard test methods:

a) To record the data and perform the calculations, use the data analysis sheets which are available on the MEMS Length and Strain Calculator web site [7],

b) Make sure the data have passed the verification given at the bottom of the data analysis sheets, and

c) Ask if all the verification checks were passed, when communicating with others concerning ASTM standard data.

\section{Acknowledgment}

First and foremost, we wholeheartedly acknowledge the many round robin participants whose combined efforts are displayed in many of the tables and figures throughout this paper. In the order of participation, we acknowledge Dr. Alexander Spivak (Kavlico), Andrew McNeil (Motorola), Dr. Herbert R. Shea (Lucent Technologies), Tom Stout and Misha Scepanovic (Veeco Metrology), Dr. Rognvald P. Garden and Eric Felkel (Zygo), Jeff Melzak and Chien Wu (FLX Micro), and Dan W. Chilcott (Delphi). Thank you!

John Huang (NIST) and Erik Secula (NIST) are acknowledged for the taking of additional round robin data and for incorporating web pages onto the SED Web site, respectively.

The following NIST people reviewed this paper: Dr. David L. Blackburn, Dr. David T. Read, Richard A. Allen, Erik M. Secula, and Dr. David G. Seiler. Thank you for the time you put into it.

And lastly, an acknowledgment to Dr. Michael Gaitan (MEMS Project Leader) and the Office of Microelectronics Programs for supporting this work.

\section{References}

[1] ASTM E08, "E 2244 Standard Test Method for InPlane Length Measurements of Thin, Reflecting Films Using an Optical Interferometer," Annual Book of ASTM Standards, Vol. 03.01, 2003.

[2] ASTM E08, "E 2245 Standard Test Method for Residual Strain Measurements of Thin, Reflecting Films Using an Optical Interferometer," Annual Book of ASTM Standards, Vol. 03.01, 2003. 
[3] ASTM E08, "E 2246 Standard Test Method for Strain Gradient Measurements of Thin, Reflecting Films Using an Optical Interferometer," Annual Book of ASTM Standards, Vol. 03.01, 2003.

[4] Taylor, B. N. and Kuyatt, C. E., "Guidelines for Evaluating and Expressing the Uncertainty of NIST Measurement Results," NIST Technical Note 1297, National Institute of Standards and Technology, September 1994.

[5] Marshall, J. C., Secula, E. M., and Huang, J., "Round Robin for Standardization of MEMS Length and Strain Measurements," SEMI Technology Symposium: Innovations in Semiconductor Manufacturing (STS: ISM), SEMICON West 2004, San Francisco, CA, July 12-14, 2004.

[6] Marshall, J. C., "MEMS Length and Strain Measurements Using an Optical Interferometer," NISTIR 6779, National Institute of Standards and Technology, August 2001.

[7] The NIST, Semiconductor Electronics Division (SED) MEMS Length and Strain Calculator web site (http://www.eeel.nist.gov/812/test-

structures/MEMSCalculator.htm) is accessible through the MEMS Project web page at http://www.eeel.nist.gov/812/44.htm.

[8] ASTM E08, "E 2244 Standard Test Method for InPlane Length Measurements of Thin, Reflecting Films Using an Optical Interferometer," Annual Book of ASTM Standards, Vol. 03.01, 2006. (Also available via http://www.astm.org.)

[9] ASTM E08, "E 2245 Standard Test Method for Residual Strain Measurements of Thin, Reflecting Films Using an Optical Interferometer," Annual Book of ASTM Standards, Vol. 03.01, 2006. (Also available via http://www.astm.org.)

[10] ASTM E08, "E 2246 Standard Test Method for Strain Gradient Measurements of Thin, Reflecting Films Using an Optical Interferometer," Annual Book of ASTM Standards, Vol. 03.01, 2006. (Also available via http://www.astm.org.)

[11] American Society for Testing and Materials, "Form and Style for ASTM Standards," ASTM, West Conshohocken, PA, March 2001. 